\title{
Responses of Lateral Geniculate Neurons That Survive Long-Term Visual Cortex Damage in Kittens and Adult Cats
}

\author{
Nina Tumosa, Maureen A. McCall, ${ }^{a}$ William Guido, and Peter D. Spear \\ Department of Psychology and Neurosciences Training Program, University of Wisconsin, Madison, WI 53706
}

\begin{abstract}
Damage to visual cortex (areas 17-19) in kittens or adult cats produces severe retrograde degeneration of neurons in the dorsal lateral geniculate nucleus (LGN). However, some neurons survive in otherwise degenerated portions of the LGN after a visual cortex lesion at any age. Previous studies have shown that there are well-defined differences in potential retinal inputs, soma size, synaptic connections, outputs, and physiological properties of output targets of the surviving LGN cells in cats that received visual cortex damage at different ages. The present experiment investigated the relationships between these differences and the responses of surviving LGN neurons to visual stimulation.

Recordings were made from surviving neurons in the degenerated A- and C-layers of the LGN in cats that had received a visual cortex lesion on the day of birth, at 8 weeks of age, or as adults (survival was 11.5-36 months). Normal adult cats were studied for comparison. The visual receptive field was mapped, and tests were carried out to classify each cell as $X, Y$, or $W$. In addition, quantitative methods were used to assess response amplitude, strength of receptive-field surround inhibition, spatial-frequency tuning to drifting or counterphased sine-wave gratings, and response to nondominant-eye stimulation for each cell.

We found that surviving cells in all LGN layers respond to light, have normal receptive-field organization, and have normal eye dominance following a lesion at any age tested. In addition, gross retinotopic organization of the LGN is normal. However, 2 main abnormalities were observed following a lesion at all 3 ages. First, there is a reduction in the percentage of $X$ cells in the A layers, from $62 \%$ in normal LGNs to about $15 \%$ in degenerated LGNs. Second, many surviving cells in both the A- and C-layers have abnormally large receptive-field centers. Other differences that were observed between normal A-layer cells and surviving A-layer cells could be attributed to the loss of $X$ cells.
\end{abstract}

These results indicate that cells within a structure that shows severe retrograde degeneration after brain damage

Received Mar. 7, 1988; revised May 9, 1988; accepted May 10, 1988.

This work was supported by United States Public Health Service Research Grants EY01916 and EY02545 (P.D.S.) and United States Public Health Service Postdoctoral Fellowships EY05756 (N.T.) and EY05879 (W.G.). We thank Ms. Kathleen Vielhuber and Ms. Scarlett Presley for their excellent technical assistance and Dr. Paul Kerlinger for assistance with statistics. We also thank Dr. Lillian Tong and Dr. Ronald Kalil for their thoughtful comments on the manuscript.

Correspondence should be addressed to Peter D. Spear, Department of Psychology, University of Wisconsin, 1202 West Johnson St., Madison, WI 53706.

Present address: Waisman Center on Mental Retardation and Human Development, University of Wisconsin, Madison, WI 53706.

Copyright (c) 1989 Society for Neuroscience $0270-6474 / 89 / 010280-19 \$ 02.00 / 0$ can maintain relatively normal function and can take part in potentially important residual neural pathways. Previous studies indicate that these residual pathways can show both anatomical and physiological compensation for the brain damage, and the present findings bear on the consequences and mechanisms of this compensation.

Damage to visual cortical areas 17-19 (or just areas 17 and 18) in kittens or adult cats produces severe retrograde degeneration of neurons in the dorsal lateral geniculate nucleus (LGN). Following visual cortex damage in adult cats, nearly all of the large and medium-size LGN neurons degenerate. Nevertheless, many small neurons survive in otherwise degenerated portions of the LGN (Chow and Dewson, 1966; Garey and Powell, 1967; Niimi and Sprague, 1970; Kalil, 1984). Visual cortex damage in young kittens produces LGN degeneration that is in many ways more severe than that following damage in adult cats. The LGN layers are more shrunken and distorted, and the overall volume of the nucleus is smaller. However, in addition to small neurons that survive the degeneration, many large, darkly staining neurons survive in all LGN layers (Doty, 1961; Wetzel et al., 1965; Tucker et al., 1968; Mize and Murphy, 1976; Cornwell et al., 1978; Murphy and Kalil, 1979; Spear et al., 1980; Kalil, 1984). These large surviving neurons are abundant in the LGN following a visual cortex lesion made as late as 18 weeks of age (unpublished observations), but very few are present following a lesion made in adult animals. Thus, the size distribution of surviving LGN neurons differs after a visual cortex lesion made in kittens or adult cats.

The retina continues to project to surviving LGN neurons following visual cortex damage in newborn and adult cats; however, reorganization occurs among the retinogeniculate synaptic contacts (Hamori and Silakov, 1980, 1981; Somogyi et al., 1982, 1984; Kalil, 1984; Kalil and Behan, 1987). For example, the number of retinal contacts made with dendrites decreases, and the number of contacts made with flat-vesicle-containing profiles increases. Although qualitatively similar reorganization occurs following visual cortex damage in newborns and adults, there are clear quantitative differences in the pattern of synaptic reorganization following damage at the 2 ages (Kalil and Behan, 1987). One purpose of the prcsent study was to examine the functional correlates of the cell-size differences and the differences in synaptic connections of LGN neurons in cats that received visual cortex damage as adults or early in life.

A second purpose was to relate the functional properties of surviving LGN neurons to differences in their inputs and outputs following visual cortex damage at different ages (see Table 1). Retinal ganglion cells undergo transneuronal relrograde degeneration following visual cortex damage at any age, but the 
Table 1. Some effects of damage to areas 17-19 at different ages ${ }^{\alpha}$

\begin{tabular}{|c|c|c|c|}
\hline \multirow[b]{2}{*}{ Characteristic } & \multicolumn{3}{|c|}{ Age at time of $17,18,19$ lesion } \\
\hline & $1 \mathrm{~d}$ & 8 weeks & Adult \\
\hline 1. Retinal X-cclls & Most lost & Most present & Most present \\
\hline 2. Large LGN cells & Many present & Many present & Few present \\
\hline 3. LGN synaptic reorganization & Present & $?$ & Present, but different \\
\hline 4. Enhanced projection to & & & \\
\hline PMLS cortex & Present & Present & Absent \\
\hline $\begin{array}{l}\text { 5. Physiological compensation } \\
\text { in PMLS cortex }\end{array}$ & Present & Present, but different & Absent \\
\hline
\end{tabular}

"The changes noted are present after long-term survival.

degeneration is much more severe following damage in kittens than in adults (Pearson et al., 1981; Tong et al., 1982; Callahan et al., 1984; Kalil, 1984; Payne et al., 1984). Physiological studies indicate that the retinal ganglion-cell loss is restricted to cells of the X-cell functional class and that about $80 \%$ of the $X$ cells are lost following visual cortex damage in newborn kittens, whereas only about $20 \%$ arc lost following damage at 4 weeks of age or later (Tong et al., 1982; Callahan et al., 1984). Thus, the potential retinal inputs to surviving LGN neurons differ following damage at different ages (Table 1, row 1).

Efferent projections of the surviving LGN cells also differ following visual cortex damage at different ages (Table 1, row 4). Anatomical studies indicate that an enhanced retinothalamocortical projection to the posteromedial lateral suprasylvian (PMLS) visual area of cortex develops after a visual cortex lesion made between the day of birth and 18 weeks of age but not after a lesion in 26-week-old or adult cats (Kalil, 1984; Tong et al., 1984). This enhanced projection to PMLS cortex arises at least partly from the LGN neurons that survive an early lesion (Kalil et al., 1979). Corresponding to the differences in inputs from the LGN, PMLS neurons show physiological compensation for an early visual cortex lesion but not for an adult lesion. However, the nature of the physiological compensation differs according to the age at which the kittens received the visual cortex lesion (Table 1, row 5) (Spear et al., 1980; Tong et al., 1984).

Thus, in addition to their differences in size and synaptic connections, surviving LGN neurons have well-defined differences in their potential retinal inputs, in their outputs, and in the physiological properties of their output targets following a visual cortex lesion at different ages. As shown in Tablc 1, different patterns of changes are present in animals that received a lesion at birth, at 8 weeks of age, or as an adult. The present study was designed to investigate the relationships between these differences and the responses of the surviving LGN neurons. By doing so, we hoped to learn more about how the surviving LGN neurons integrate and transmit altered retinal information to efferent target structures following visual cortex damage at different ages. From this, we hoped to learn more about the nature and mechanisms of the compensation that can occur following early visual cortex damage.

\section{Materials and Methods}

\section{Subjects}

Sixteen normal adult cats (at least 9 months old) were obtained from authorized vendors. Six of these cats received a unilateral visual cortex lesion (AVC cats), and the remaining 10 served as unoperated controls (normal cats). Fifteen kittens were born in the laboratory breeding colony. Seven received a unilateral visual cortex lesion on the day of birth
(KVC-1D cats) and 8 received a unilateral lesion at 7-8 weeks of age (KVC-8WK cats). Physiological recordings were unsuccessful in 8 of the animals with a visual cortex lesion, either because we were unable to locate the LGN during recording or because histological analysis showed the recordings to have been entirely from undegenerated portions of the nucleus. Successful recordings were made from $4 \mathrm{KVC}-1 \mathrm{D}$, $4 \mathrm{KVC}-8 \mathrm{WK}$, and $5 \mathrm{AVC}$ cats (see Table 2). Further descriptions refer only to these animals.

Kittens remained with their mothers until weaning. All cats were housed in large group cages with shelves for climbing. The colony rooms were kept on an $18 \mathrm{hr} / 6 \mathrm{hr}$ light/dark cycle. Electrophysiological recordings were carried out 11.5-36 months after the visual cortex lesions were made.

\section{Cortical lesions}

Unilateral visual cortex lesions were made by aspiration using sterile procedures, as described previously (Spear and Baumann, 1979; Spear et al., 1980). Adult cats were anesthetized with pentobarbital sodium and kittens were anesthetized with halothane. The lesions were intended to include the cortex of the lateral and postlateral gyri, the posterior bend of the suprasylvian gyrus, and the splenial cortex on the medial wall of the hemisphere, i.e., areas 17, 18, and 19 (Otsuka and Hassler, 1962; Tusa et al., 1978, 1979). Adult cats were kept in individual cages during initial rccovcry and were then returned to the colony room. Kittens were placed in an incubator until they recovered from anesthesia and could be returned to their mothers.

\section{Electrophysiological procedures}

Animal preparation. Each cat was prepared for single-cell recordings in the LGN using standard procedures (Spear et al., 1982; Crabtree et al., 1986). During all surgery, the cat was anesthetized with halothane in $50 \% \mathrm{O}_{2} / 50 \% \mathrm{~N}_{2} \mathrm{O}$. The animal was mounted in a specially designed stereotaxic apparatus that leaves the visual field free from obstruction. Paralysis was induced and maintained throughout recording by continuous intravenous infusion of gallamine triethiodide. A bilateral cervical sympathectomy also was performed to achieve greater eye stability. The cat was artificially respired via a tracheal cannula and end-expired $\mathrm{CO}_{2}$ was monitored and maintained around $4 \%$. Heart rate was monitored continuously, and body temperature was maintained near $37.5^{\circ} \mathrm{C}$ with a heating blanket. All wound edges were infiltrated with a long-lasting (oil-based) local anesthetic. During recording the animal was anesthetized with $0.5 \%$ halothane in $\mathrm{O}_{2}$.

Trephine holes were made in the skull over the LGN of both hemispheres, and the dura was excised. A plastic well was cemented in place over each skull opening, filled with agar/sucrose gel, and sealed with petroleum jelly to reduce brain pulsations during single-unit recording. A pair of stimulating electrodes was inserted into the brain so that the tips straddled the optic chiasm (OX).

The pupils were dilated, and accommodation was blocked by topical application of $1 \%$ ophthalmic atropine sulfate. Retinal landmarks were projected on to a tangent screen using a fiber-optic light source (Pettigrew et al., 1979), and the positions of the areae centrales were plotted and checked periodically throughout the experiment. The corneas were protected with zero-power contact lenses that were opaque except for a 3 $\mathrm{mm}$ diameter artificial pupil. Spectacle lenses were used to focus the 
eyes on a tangent screen or an electronic display monitor placed 57 or $28.5 \mathrm{~cm}$ from the nodal point.

Single-cell recording and sampling procedures. Extracellular singlecell recordings were made with varnish-coated tungsten microelectrodes. Electrode impedance was $45-75 \mathrm{M} \Omega$, measured with a $135 \mathrm{~Hz}$ sine-wave input. In normal cats, the LGN war. located on the basis of stereotaxic coordinates. It was more difficult to locate the LGN ipsilateral to a visual cortex lesion because of the severe shrinkage of the degenerated LGN, especially in KVC-1D and KVC-8WK cats. Therefore, the LGN of the undamaged hemisphere was located first. Then, based on the location of the LGN on the undamaged side, a penetration was placed in the hemisphere ipsilateral to the visual cortex lesion at coordinates calculated to put the electrode in the middle of the LGN.

Action potentials from each isolated cell were amplified, monitored with an audio monitor, and displayed on an oscilloscope. The criteria of Bishop et al. (1962a) and the presence of latency variability to OX stimulation were used to distinguish axon from cell-body recordings. All results are from postsynaptic LGN neurons. Action potentials were led through a window-discriminator to a PDP-11/34 computer. Peristimulus time histograms (PSTHs) of cellular responses to repeated stimuli could be produced on-line or stored for later analysis.

While searching for single-cell recordings in the LGN, the electrode was advanced slowly in $5 \mu \mathrm{m}$ steps, and spots of light were moved or flashed on the tangent screen. Once a penetration was started through the LGN, it was terminated only after the A- and C-layers had been traversed completely. In degenerated LGNs, data were collected from all cells encountered in all layers. In LGNs of normal cats, data were collected from all cells encountered in the C-layers but usually from only the first 1 or 2 cells encountered in each of layers $A$ and $A 1$. We restricted our sample from layers $A$ and $A 1$ in normal cats so that we could spend more time recording in the C-layers. This allowed us to obtain relative sample sizes from the A- and C-layers of normal cats that were similar to those in cats with a visual cortex lesion.

\section{Visual and electrical stimulation}

Visual stimuli were presented on the tangent screen using a hand-held projector. Flashed spots of light were used to determine receptive-field location and center type (e.g., On, Off, or On/Off center) and to map the borders of the receptive-field center. Then the tangent screen was replaced with a Hewlett-Packard $1332 \mathrm{~A}$ display monitor (P-31 phosphor), which was positioned so that the receptive field was centered on the display-monitor screen. In most cases, the display screen was placed $57 \mathrm{~cm}$ from the nodal points of the eyes and was $12^{\circ}$ wide $\times 10^{\circ}$ high However, if the cell had a large receptive field (diameter $\geq 5^{\circ}$ ), the display screen was placed $28.5 \mathrm{~cm}$ from the nodal points and was $24^{\circ}$ wide $\times$ $20^{\circ}$ high. Vertical sine-wave grating stimuli were presented on the display monitor under the control of an Innisfree image generator, which was controlled by the PDP-11/34 computer. Mean luminance of the gratings was $30 \mathrm{~cd} / \mathrm{m}^{\prime}$. Pcak-to-pcak contrast of the gratings generally was $60 \%$. However, occasional cells did not respond to this contrast, in which case a contrast of $80 \%$ was used. Spatial frequencies of the gratings could be varied between 0.1 and $5.4 \mathrm{c} / \mathrm{deg}$ (screen distance $57 \mathrm{~cm}$ ) or 0.05 and $2.7 \mathrm{c} / \mathrm{deg}$ (screen distance $28.5 \mathrm{~cm}$ ). The gratings could be drifted or counterphase-modulated (contrast-reversed) at a wide range of temporal frequencies. Light or dark spots of different diameters also could be presented on the display monitor under computer control. Light spots had a luminance of $55 \mathrm{~cd} / \mathrm{m}^{2}$ and dark spots had a luminance of $3 \mathrm{~cd} / \mathrm{m}^{2}$ on a background screen luminance of $30 \mathrm{~cd} / \mathrm{m}^{2}$.

All cells gave a brisk response to only one eye (the dominant eye), and they were tested initially through that eye. Some cells also were tested through the other (nondominant) eye. In these cases, the displaymonitor screen was placed $28.5 \mathrm{~cm}$ from the nodal point and centered on the visual-ficld location for the nondominant eye that corresponded to the location of the receptive-field center for the dominant eye. While testing either eye, the other eye was covered with an opaque occluder.

Bipolar electrical stimulation of the OX was delivered via a constantcurrent stimulus-isolation unit. Stimuli were $50 \mu \mathrm{sec}$ pulses, and current was varied between 0.1 and $10 \mathrm{~mA}$. Response latency of $L G N$ cells was tested with electrical stimuli repeated at a rate of $0.5-1 / \mathrm{sec}$. Responses were stored on an oscilloscope, and latency was measured from the beginning of the stimulus pulse to the foot of the action potential.

\section{Quantitative measures of responses to visual stimuli}

Spatial-frequency response functions to drifting gratings. To assess responses to different spatial frequencies, vertical sine-wave gratings were drifted across the receptive field. Each neuron was presented with 7 spatial frequencies that varied in approximately 1 -octave steps. On a given trial, one spatial frequency was presented for $1 \mathrm{sec}$ at a drift rate (temporal frequency) of $3 \mathrm{~Hz}$. A run consisted of all 7 spatial frequencies (one trial of each) plus a blank trial in which the display screen had a uniform luminance of $30 \mathrm{~cd} / \mathrm{m}^{2}$. A $5 \mathrm{sec}$ intertrial interval $\left(30 \mathrm{~cd} / \mathrm{m}^{2}\right.$ uniform luminance) separated cach of the 8 trials in a run. Ten to 20 such runs were presented to each cell. The only exception to this protocol was that cells in the first 10 animals studied were tested with 5 runs of 3-sec-long trials. In all cases, the order of presentation was semirandom within each run, and a different order of presentation was used in each run.

Data from each trial were stored in a 100-bin PSTH. The PSTH for each trial was subjected to a Fourier analysis to determine the amplitude of the modulated discharge at the fundamental frequency of the stimulus (F1) and the mean discharge rate (F0) for that trial. To exclude the initial response transient that sometimes occurs when the grating stimulus first appears on the display screen, the first $90 \mathrm{msec}$ of each PSTH was excluded from the Fourier analysis. Thus, only the steady-state response to the drifting grating was analyzed. The means and SEs of the F0 and $\mathrm{F} 1$ responses were then calculated for all trials of a given spatial frequency. A similar Fourier analysis was carried out for the maintained discharge during presentation of a blank screen, as if a $3 \mathrm{~Hz}$ drifting grating were present. This provided a measure of the mean maintained discharge rate $(\mathrm{F} 0)$ and of the inherent $3 \mathrm{~Hz}$ activity $(\mathrm{F} 1)$ of the cell. A spatial-frequency response function was then plotted that showed the means \pm SEs of the F0 or F1 responses to each spatial frequency and the inherent F0 or F1 discharge when no stimulus was present (see Fig. 7).

Two measures of spatial-frequency processing were made from the spatial-frequency response functions. Spatial resolution was defined as the highest spatial frequency to which the cell gave a statistically significant response. To determine statistical significance, a $t$ test was performed comparing the mean $\pm \mathrm{SE}$ of the response to the grating of a particular spatial frequency with the mean \pm SE of the maintained discharge when no stimulus was present. A 1-tailed probability of $\leq 0.05$ was considered statistically significant. Optimal spatial frequency was defined as the spatial frequency to which the cell gave the greatest response. Spatial resolution and optimal spatial frequency were determined for both the F0 and F1 responses.

Spatial resolution to counterphased gratings. Stationary sine-wave gratings were counterphase-modulated (contrast-reversed) to determine the spatial resolution of any second harmonic $(\mathrm{F} 2)$ response that was present (i.e., any response at twice the contrast-reversal frequency). Grating contrast was modulated using a $3 \mathrm{~Hz}$ sine-wave function. Previous studies have shown that when a second-harmonic response is present for LGN cells, F2 response amplitude is spatial-phase invariant for spatial frequencies that are high for the cell (Shapley and Hochstein, 1975; So and Shapley, 1979; Sur and Sherman, 1982). Therefore, because our purpose was to determine spatial resolution, no attempt was made to present the gratings at a particular spatial phase. However, spatial phase was the same for all trials of a given spatial frequency. Ten to 20 runs of 7 spatial-frequency trials plus a blank trial were presented using the same protocol as for drifting gratings. The PSTHs were analyzed as described for drifting gratings except that only the F2 response amplitude was determined. Spatial resolution was defined as the highest spatial frequency to which the cell gave a statistically significant F2 response when compared with the inherent F2 $(6 \mathrm{~Hz})$ discharge during presentation of a blank screen.

Area-response functions. To assess responses to spots of different sizes, circular spots were flashed on for $1 \mathrm{sec}$ and then off for $1 \mathrm{sec}$ over the center of the receptive field. Light spots were used for cells with an Oncenter receptive field, and dark spots were used for cells with an Offcenter or an On/Off-center receptive field. Spot diameter ranged from $0.5^{\circ}$ to $10^{\circ}$ (screen distance $57 \mathrm{~cm}$ ) or $1^{\circ}$ to $20^{\circ}$ (screen distance 28.5 $\mathrm{cm}$ ). Within a run, each of 6 different spot diameters plus a blank screen were presented in semirandom order, and 20 runs were presented. To determine peak response rate, the computer found the PSTH bin with the largest number of spikes during the stimulus-on period and then averaged the number of spikes in that bin and the bin to either side of it ( $75 \mathrm{msec}$ total for the 3 bins). This was done for each trial, and then the mean $\pm S E$ of the peak response rate was calculated for the 20 trials with each spot diameter. To obtain a measure of peak maintained discharge rate, the computer averaged the number of spikes in the first 3 PSTH bins during presentation of the blank screen. Area-response functions of peak response versus spot diameter were then plotted. 
Two measures were taken from the area-response functions. Optimal stimulus size was the spot diameter that produced the largest peakresponse rate. Strength of surround inhibition was the percentage reduction in peak-response rate that occurred when the cell was stimulated with the largest spot compared with the optimal spot size. The formula used was

$$
S=\{[(O-B)-(L-B)] /(O-B)\} \times 100,
$$

where $S$ is strength of surround inhibition, $O$ is peak response to the optimal stimulus size, $L$ is peak response to the largest stimulus, and $B$ is peak maintained discharge during presentation of a blank screen.

\section{Between-group statistical comparisons}

For each receptive-field or response property that was assessed, statistical analyses were carried out to determine if animals with a visual cortex lesion at different ages differed from each other and from normal animals. For these analyses, results from all cells tested for a particular property were pooled across animals in each group (normal, AVC, KVC$8 \mathrm{WK}, \mathrm{KVC}-1 \mathrm{D}$ ). The 4 groups then were compared using a l-way analysis of variance (ANOVA). If a significant overall effect was present ( $p \leq 0.05,2$-tailed), then Scheffé tests (1-tailed) were used to determine if the lesion groups differed from each other. If they did not differ from cach other, results from all cells in the lesion groups were combined for comparison with normal cells using a $t$ test (2-tailed). If the lesion groups did differ, Scheffe tests were used to compare each lesion group separately with normals. Exceptions to these procedures are noted in Results.

These statistical procedures assume that results from all cells studied in a given cat are independent of each other. We believe that this is a valid assumption because, on average, only 2.2 cells were studied in the same layer in a given microelectrode penetration. Therefore, any tendency for cells with similar properties to cluster together within an LGN layer is unlikely to affect the results.

\section{Histology}

In each hemisphere studied, the location of the electrode tip was marked with a small electrolytic lesion at 2 positions along at least one microelectrode penetration. At the end of the recording session, the cat was given a deep anesthetic dose of pentobarbital sodium and perfused transcardially with $0.9 \%$ saline followed by $10 \%$ formal saline. Frozen sections through the brain were cut at $30 \mu \mathrm{m}$ in the coronal plane, mounted on slides, and stained with cresyl violet. All electrode tracks from which data are reported were located in the sections and used to reconstruct the location of cells that were recorded.

The lesions were reconstructed from photographs and drawings of the damaged hemisphere that were made after the brain had been removed from the skull. Using criteria described elsewhere (Wood et al., 1974; Spear and Baumann, 1979; Spear et al., 1980), the reconstructions and especially the pattern of retrograde degeneration in the LGN and medial interlaminar nucleus (MIN) were used to assess the extent to which areas 17-19 were removed.

\section{Results}

Cortical lesions and $L G N$ degeneration

All cortical lesions included part or all of the splenial gyrus, the lateral and postlateral gyri, and the posterior bend of the suprasylvian gyrus. Thus, all of the lesions included portions or all of areas 17-19. In some cases, parts of the middle and posterior suprasylvian gyri also were damaged or undercut. Lesions similar to those in the present study are illustrated elsewhere (Spear et al., 1980).

Figure 1 illustrates the appearance of the degenerated LGN in a cal from each lesion group and shows a microelectrode track through the LGN in each case. All data reported for cats with a visual cortex lesion were from cells histologically verified to be in degenerated portions of the LGN. Both A- and C-layers normally project to areas 17 and 18 (see Rosenquist, 1985; Spear, 1985, for reviews), and the severe degeneration in these layers indicates that topographically corresponding parts of both areas 17 and 18 had been removed (Garey and Powell, 1967; Niimi and Sprague, 1970; Burrows and Hayhow, 1971). Cells in the C-layers normally project to area 19 , as well as to areas 17 and 18 (Rosenquist, 1985; Spear, 1985), and it is difficult to distinguish between C-layer degeneration after damage to areas 17 and 18 and that after damage to areas 17-19. However, degeneration in the MIN can be taken as an indication that area 19 was damaged (Garey and Powell, 1967; Niimi and Sprague, 1970). Analysis of the MIN suggests that for $35 \%$ of the C-layer cells in KVC-1D cats, $22 \%$ in KVC- 8 WK cats, and $75 \%$ in AVC cats, the topographically corresponding part of area 19 also had been removed. The samples of C-layer cells with and without area 19 removed at each age were too small to make detailed statistical comparisons. However, there were no obvious differences in results among (-layer cells with areas 17 and 18 removed and those with areas 17-19 removed. Therefore, results from all C-layer cells are presented together.

\section{Cell sample and qualitative description of responses}

In agreement with previous studies, virtually all of the LGN cells in normal cats gave clear excitatory responses to stimulation of only one eye. In addition, individual cells and multiunit background activity displayed alternating eye affiliations as the electrode advanced through the LGN layers from dorsal to ventral: contralateral eye in layer A, ipsilateral in A1, contralateral in $\mathrm{C}$, ipsilateral in $\mathrm{C} 1$, and contralateral in $\mathrm{C} 2$. The same pattern was seen in cats with a visual cortex lesion at any age (see Fig. 2).

On the basis of the pattern of eye alternation and microelectrode track reconstructions, it was possible to determine the layers in which cells were recorded. This could be done unequivocally for cells in layers A and Al. In addition, it always was clear when the electrode entered the C-layers. However, the 3 C-layers are not separated by clear cytoarchitectonic borders and, in penetrations in which no ipsilateral-eye cells were encountered (layer $\mathrm{Cl}$ ), it was difficult to be sure whether contralateral-eye cells were in layer $\mathrm{C}$ or $\mathrm{C} 2$. These were designated as $\mathrm{C} / \mathrm{C} 2$ cells. Table 2 shows the numbers of cells sampled in each layer for each group of cats.

In all groups, all cells encountered in the A layers responded to light and had either On- or Off-center receptive fields. In addition, all but 5 A-layer cells ( 3 in KVC.8WK and 2 in AVC, cats) had well-defined receptive-field borders that could be mapped readily on the tangent screen. Cells that failed to respond to light were found only in the C-layers. They comprised $3.4 \%$ of the C-layer cells in normal cats, $0 \%$ in KVC- $1 \mathrm{D}$ cats, $0 \%$ in KVC- $8 \mathrm{WK}$ cats, and $12 \%$ in AVC cats. Most C-layer cells also had well-defined On- or Off-center receptive fields. However, some C-layer cells had On/Off centers and some responded better to moving than to flashed stimuli. In addition, about $15 \%$ of the C-layer cells had only poorly defined receptivefield borders. These properties have been reported previously for normal C-layer cells (Cleland et al., 1976; Wilson et al., 1976; Sur and Sherman, 1982; Frascella and Lehmkuhle, 1984; Spear et al., 1989), and we found no differences in their incidence between normal cats and cats with a visual cortcx lcsion at any age. Thus, the basic receptive-field organization of surviving $A-$ and C-layer cells generally appeared to be normal.

The visuotopic map also seemed relatively normal in the degenerated LGN of all groups. Even though receptive-field size was abnormally large (see below), the receptive-field center locations were similar to normal. Thus, nearby cells in a given layer had nearby receptive fields, and cells in adjacent layers (respresenting opposite eyes) had receptive fields in approxi- 

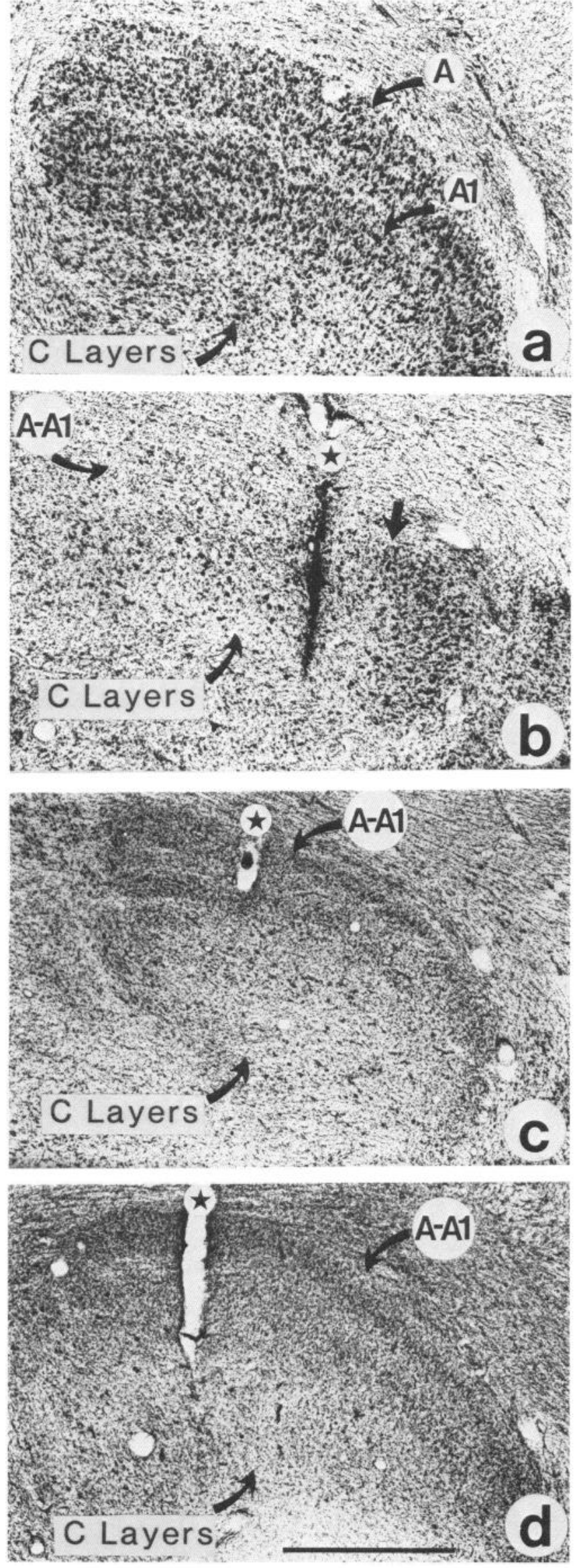

mately homologous visual field positions for the 2 eyes (see Fig. 2). Furthermore, anterior-posterior or medial-lateral movement of the microelectrode produced movement of visual field location that could be predicted from Sanderson's (1971b) maps of the normal LGN, except that smaller than normal electrode movements were required because the degenerated LGN is smaller than normal.

\section{Receptive-field center size}

Figure 3 shows plots of receptive-field center diameter as a function of retinal eccentricity for cells with receptive fields that could be mapped on the tangent screen. In both the A- and C-layers, the distributions of eccentricities sampled were similar for all groups. Therefore, cells with all receptive-field eccentricities were combined for comparisons of receptive-field size.

In the A-layers of KVC-1D and AVC cats, surviving cells in the degenerated LGN had larger receptive fields than normal A-layer cells (Fig. 3, left). This was the result of 2 effects. First, the proportion of cells with receptive fields $>5^{\circ}$ diameter was significantly greater than normal for each of these lesion groups ( $\chi^{2}$ tests, $p<0.01,2$-tailed). Second, the proportion of cells with very small receptive fields $\left(<1^{\circ}\right.$ diameter $)$ was significantly lower than normal for the KVC-1D and AVC cats ( $\chi^{2}$ tests, $p$ $<0.05$ ). These differences did not reach statistical significance in the KVC-8WK cats, perhaps because the sample of cells was so small $(n=13)$.

Receptive-field center size also was abnormally large for cells in the degenerated C-layers (Fig. 3, right). For all 3 lesion groups, the proportion of cells with large receptive fields $\left(>5^{\circ}\right)$ was significantly greater than normal $\left(\chi^{2}\right.$ tests, $\left.p<0.05\right)$. Few $C$-layer cells have very small receptive-field centers in normal cats, and accordingly there was no significant reduction in the proportion of such cells following a visual cortex lesion at any age.

\section{Linearity of spatial summation}

Linearity of spatial summation was assessed using a counterphased sine-wave grating ( $3 \mathrm{~Hz}$ counterphase rate, $60 \%$ contrast) with a spatial frequency just below the cutoff for the cell being studied. The grating was stepped across the receptive field in different spatial-phase positions. Cells with linear spatial summation have a phase position at which the cell ceases to respond (a null point). Cells with nonlinear summation have no null point; rather, these cells show response doubling (a temporal nonlinearity) at all spatial-phase positions (Enroth-Cugell and Robson, 1966; Hochstein and Shapley, 1976). In the A-layers of normal cats, about $60 \%$ of the cells showed linear spatial summation, about $35 \%$ of the cells showed nonlinear spatial

\footnotetext{
Figure 1. Photomicrographs of cresyl violet-stained coronal sections through the LGN of a normal cat (a), a KVC-1D cat (b), a KVC-8WK cat $(c)$, and an AVC cat $(d)$. There is severe retrograde degeneration of LGN neurons in cats with a visual cortex lesion. Nevertheless, small neurons survive in all cases, and large, darkly stained neurons can be seen scattered throughout otherwise degenerated portions of the LGN in the KVC-1D and KVC-8WK cats. In $b$, the lateral part of the LGN (to the right of the unlabeled straight arrow) is not degenerated, indicating that the corresponding portions of cortical areas 17 and 18 were spared. However, the medial part of the LGN (left of arrow) is degenerated as a result of removal of the corresponding portions of areas 17 and 18 . The sections in $b-d$ include a microelectrode track (marked by a star) from which surviving LGN neurons were recorded. In all cases, the microelectrode passed through the degenerated part of the LGN. Scale bar, $1.0 \mathrm{~mm}$. Layers A-A1 and C are indicated.
} 


\section{1-DAY LESION}<smiles>c1ccc2cccc-2cc1</smiles>

\section{(a)}
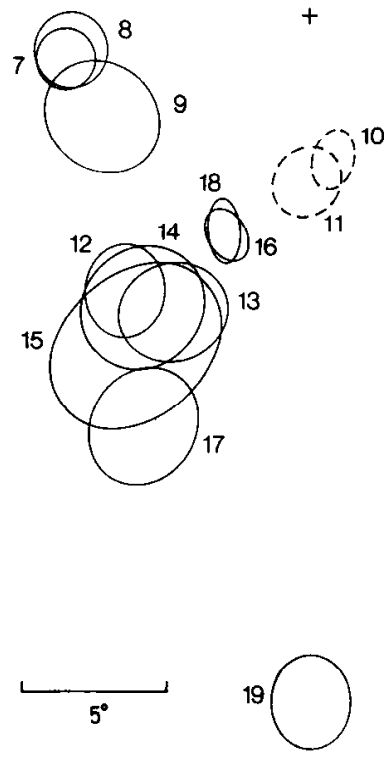

NORMAL

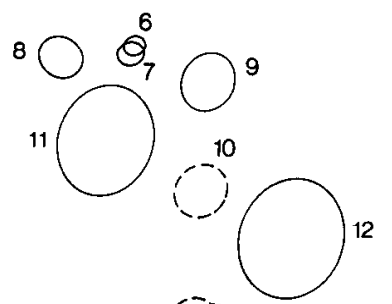

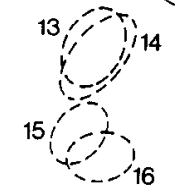

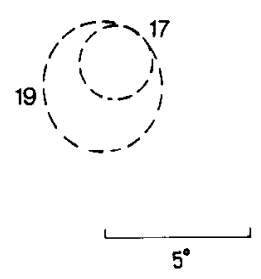

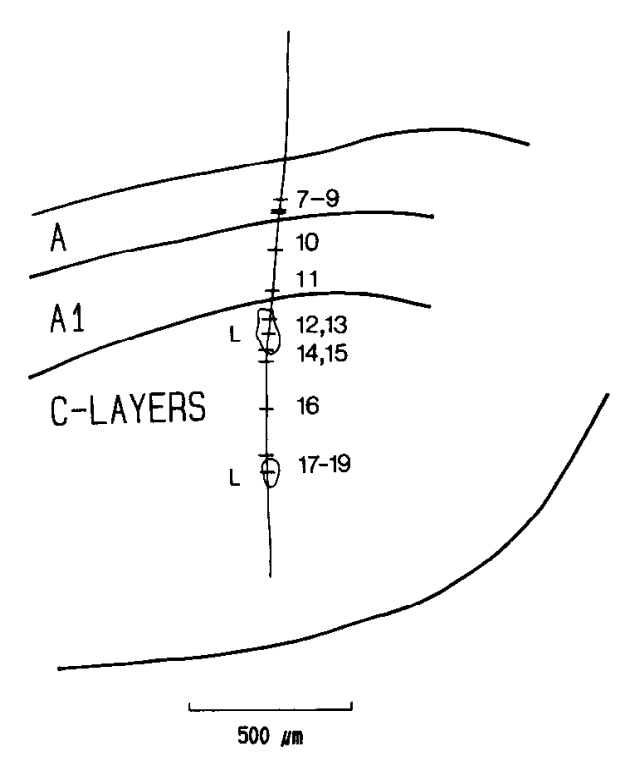

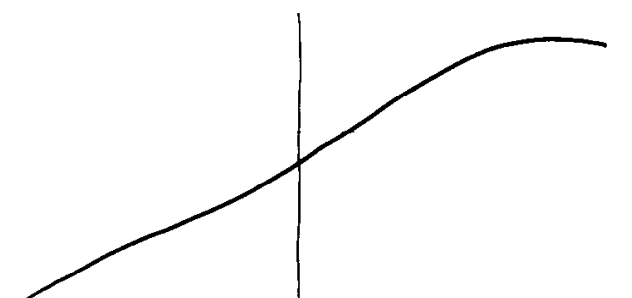

Figure 2. Reconstruction of a microelectrode penetration through the LGN of a cat that had received a visual cortex lesion on the day of birth (top) and a normal cat (bottom). Camera lucida drawings of the LGN and microelectrode track were made from cresyl violet-stained coronal sections. Electrolytic marking lesions are drawn and indicated by $L$. The positions of single neurons recorded were determined from microdrive readings during recording and are indicated by tic marks along the microelectrode track. The drawings at left show the receptive-field centers that were mapped on the tangent screen for each cell. The areae centrales of the 2 eyes have been superimposed and are represented by a + in the figure. Outline drawings are receptive fields for the contralateral eye and dashed lines are receptive fields for the ipsilateral eye. Numbers correspond to the cell numbers in the electrode track reconstructions. No layer $\mathrm{Cl}$ cells (ipsilateral eye) were encountered in the penetration in the KVC-1D cat (top), and no layer $\mathrm{C} 2$ cells (contralateral eye after layer $\mathrm{Cl}$ ipsilateral eye cells) were encountered in the penetration in the normal cat (bottom). Cell 18 in the normal cat was unresponsive to light. summation, and about $5 \%$ failed to respond to the grating at any phase position (Fig. 4, top). ANOVA tests revealed a significant effect of the visual cortex lesion on the proportions of A-layer cells with linear or nonlinear spatial summation $(p<$ 0.05 for each property). Scheffé tests showed no significant dif- ferences among the 3 lesion groups, and $t$ tests indicated that the 3 lesion groups combined had a significant increase in the proportion of cells with nonlinear spatial summation $(p<0.05)$ and a concomitant decrease in the proportion of cells with linear spatial summation $(p<0.05)$. In the C-layers, ANOVA tests 
A LAYERS

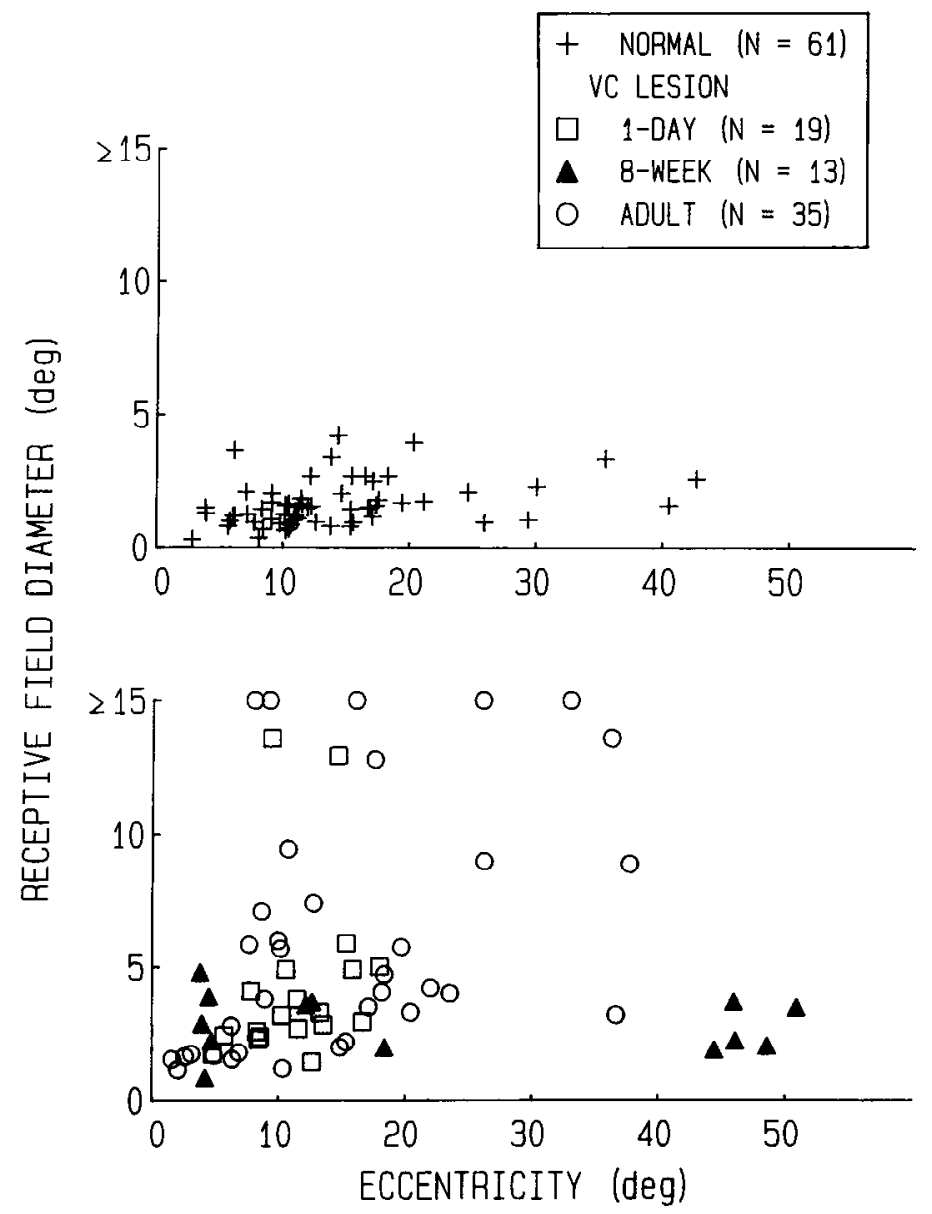

C LAYERS
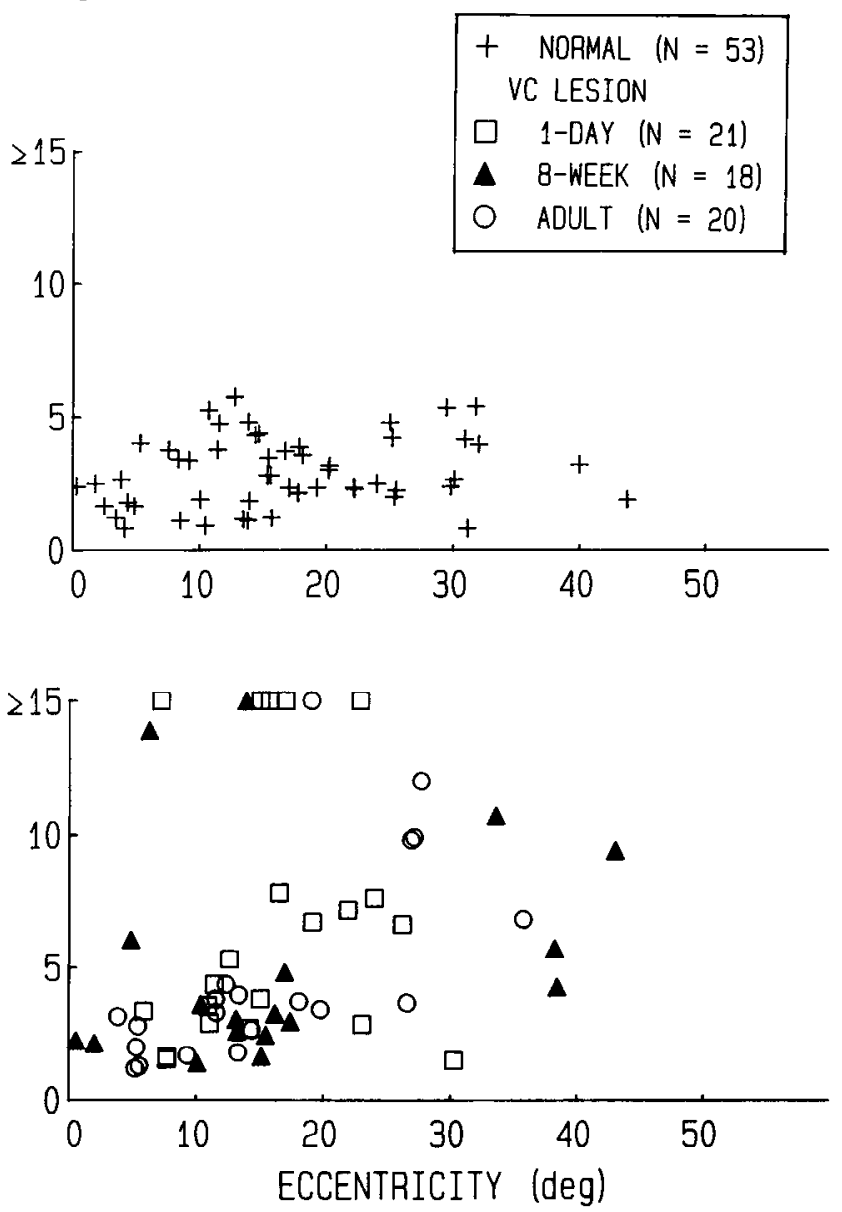

Figure 3. Receptive-field center diameter as a function of eccentricity from area centralis for cells with receptive fields that could be mapped on the tangent screen. Data are presented separately for cells recorded in the A-layers (A and A1 combined; left) and C-layers (C, Cl, and C2 combined; right). Results for normal animals are shown at the top, and results for surviving LGN cells in cats with a visual cortex lesion at different ages are shown at the bottom. $N$, number of cells with receptive fields mapped in each condition.

indicated that there was no significant effect of the visual cortex lesion on the proportions of cells with linear or nonlinear spatial summation (Fig. 4, bottom).

\section{Response latency to $O X$ stimulation}

Modal response latency to repeated OX shocks was determined for each cell that responded to OX stimulation. In the A-layers of normal cats, nearly all responsive cells had latencies between 1.0 and $2.5 \mathrm{msec}$ (Fig. 5, top left). There were no significant differences in response latencies among the 3 visual cortex lesion groups (Fig. 5, bottom left). Overall, response latencies among surviving A-layer cells were significantly shorter than normal $(t$ test, $p<0.05$ ). This decrease was due to a reduced proportion of cells with latencies between 1.6 and $2.5 \mathrm{msec}$ (arrows in Fig. 5 ) and a concomitant increase in the proportion of cells with latencies shorter than $1.6 \mathrm{msec}$ ( $\chi^{2}$ test, $p<0.001$ ).

In the C-layers of normal cats, cells that responded to $\mathrm{OX}$ stimulation tended to have latencies that were either very short $(<1.6 \mathrm{msec})$ or very long $(>2.5 \mathrm{msec})$. The distributions of response latencies were not significantly different from normal in all groups with a visual cortex lesion (Fig. 5, right).

Table 2. Number and distribution of cells recorded in the LGN for each group

\begin{tabular}{|c|c|c|c|c|c|c|c|c|c|}
\hline \multirow[b]{2}{*}{ Group } & \multirow{2}{*}{$\begin{array}{l}\text { No. of } \\
\text { cats }\end{array}$} & \multirow{2}{*}{$\begin{array}{l}\text { No. of } \\
\text { pens }^{a}\end{array}$} & \multicolumn{7}{|c|}{ Number of cells studied in each layer } \\
\hline & & & $\mathrm{A}$ & Al & $\mathrm{C}$ & $\mathrm{Cl}$ & $\mathrm{C} 2$ & $\mathrm{C} / \mathrm{C}^{b}$ & Total \\
\hline Normal & 10 & 21 & 29 & 32 & 30 & 18 & 10 & 0 & 119 \\
\hline KVC-1D & 4 & 8 & 11 & 8 & 6 & 2 & 1 & 14 & 42 \\
\hline KVC-8WK & 4 & 8 & 9 & 7 & 14 & 7 & 2 & 0 & 39 \\
\hline AVC & 5 & 7 & 24 & 13 & 9 & 3 & 0 & 12 & 61 \\
\hline
\end{tabular}

${ }^{a}$ Number of microelectrode penetrations from which data were obtained.

${ }^{b}$ Cells sampled in the $C$-layers and driven by the contralateral eye but which could not be assigned with confidence to layer $\mathrm{C}$ or $\mathrm{C} 2$. 


\section{Classification of $L G N$ cells}

The 3 properties described so far-receptive-field center size, modal response latency to $\mathrm{OX}$ stimulation, and linearity of spatial summation - are commonly used to distinguish $X, Y$, and W cells in the LGN (e.g., Shapley and Hochstein, 1975; Wilson et al., 1976; Kratz et al., 1978; So and Shapley, 1979; Sur and Sherman, 1982; see also Cleland et al., 1971, 1976). X cells are characterized by a receptive-field center diameter of $<1^{\circ}$, latency to OX stimulation of $>1.6 \mathrm{msec}$ and linear spatial summation. $Y$ cells have a receptive-field center diameter of $\geq 1^{\circ}$, latency to OX stimulation of $\leq 1.6 \mathrm{msec}$, and nonlinear spatial summation. W cells are characterized by a receptive-field center diameter of $\geq 1^{\circ}$ combined with a latency to OX stimulation of $\geq 2.5 \mathrm{msec}$, W cells may have either linear or nonlinear spatial summation (Sur and Sherman, 1982; Spear et al., 1989), so this property does not distinguish them from $\mathrm{X}$ or $\mathrm{Y}$ cells. Howcver, an additional property that aids in the classification of $\mathrm{W}$ cells is the presence of an unusual receptive-field organization, such as an On/Off receptive-field center or optimal responses to moving rather than stationary flashed stimuli (Wilson et al., 1976; Sur and Sherman, 1982; Spear et al., 1989). Using these criteria, we classified each of the cells in our sample as $\mathrm{X}$, $\mathrm{Y}$, or W. Cells that had mixed properties or that responded too poorly to be classified with confidence were considered as unclassified (UC). Cells for which insufficient data were obtained on the tests were excluded from this analysis.

Figure 6 shows the percentages of cells classified as X, Y,W, or UC in the A- and C-layers of each group of cats. In the A-layers of normal cats, $62 \%$ of the cells encountered were classified as X cells and $28 \%$ were classified as $\mathrm{Y}$ cells, percentages that agree with previous reports (e.g., Hoffmann et al., 1972; Cleland et al., 1976; Wilson et al., 1976; Spear et al., 1982; Friedlander and Stanford, 1984; Crabtree et al., 1986; McCall et al., 1987). About $10 \%$ of the cells were classified as $W$ cells or UC. All 3 groups with a visual cortex lesion had a reduced proportion of $\mathrm{X}$ cells encountered in the degenerated A-layers of the LGN: $21 \%$ were X cells in the KVC-1D cats, $8 \%$ in KVC$8 \mathrm{WK}$, and $16 \%$ in $\mathrm{AVC}\left(\chi^{2}\right.$ tests, $p<0.01$ in each case). The reduced encounter rate of $X$ cells was seen consistently among individual cats, and statistical comparisons that treat each cat as a single observation confirm the reduction for each group (2tailed Mann-Whitney tests comparing normal cats with cats in each lesion group: $U=1, p=0.02$ for KVC-1D; $U=0, p=$ 0.002 for KVC-8WK; $U=1, p=0.002$ for AVC). Concomitant with the decrease in $\mathrm{X}$ cells encountered there was an increase in the percentage of $Y$ cells encountered in the degenerated A-layers for all 3 groups ( $\chi^{2}$ tests, $p<0.01$ ). However, there was no consistent change in the percentages of $W$ or UC cells.

In the C-layers of normal cats, about $45 \%$ of the cells were $Y$ cells. Most of the Y cells (15 of 19) were encountered in layer $\mathrm{C}$, and the remainder ( 4 of 19 ) were in layer $\mathrm{Cl}$. About $35 \%$ of the C-layer cells were W cells. Most of these (11 of 15$)$ were encountered in layers $\mathrm{Cl}$ and $\mathrm{C} 2$, though some (4 of 15) were present in layer $\mathrm{C}$. Only $2 \mathrm{X}$ cells were encountered, both in layer $C$. The percentages of cells in each class were somewhat variable among cats with a visual cortex lesion (Fig. 6, bottom); however, there were no significant differences among the 3 groups or between any of the lesion groups and normal cats.

\section{Spatial-frequency response functions to drifting gratings}

Figure 7 shows examples of spatial-frequency response functions for neurons in normal and degenerated LGNs. All cells respond-

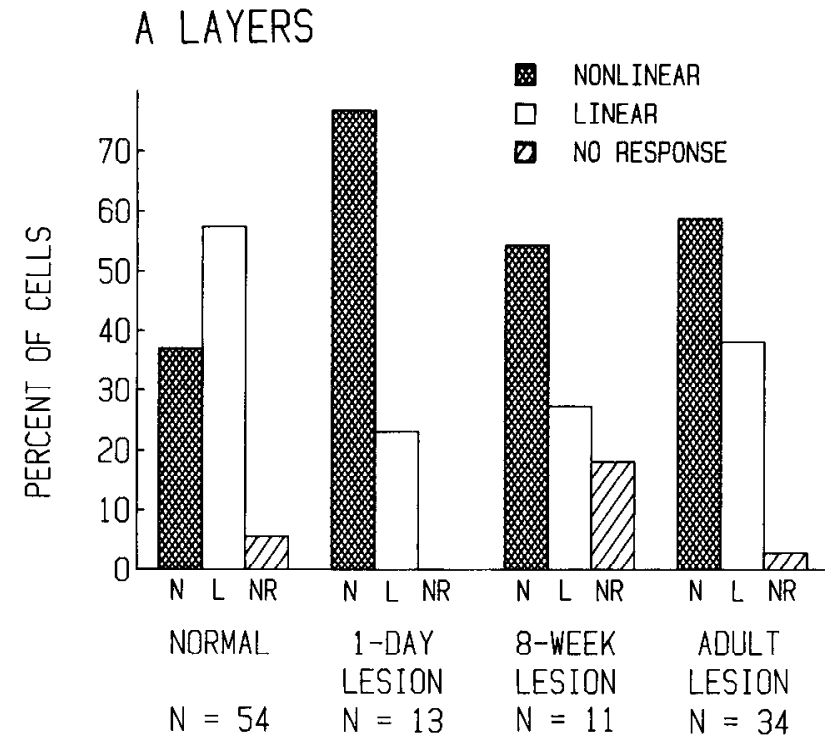

\section{LAYERS}

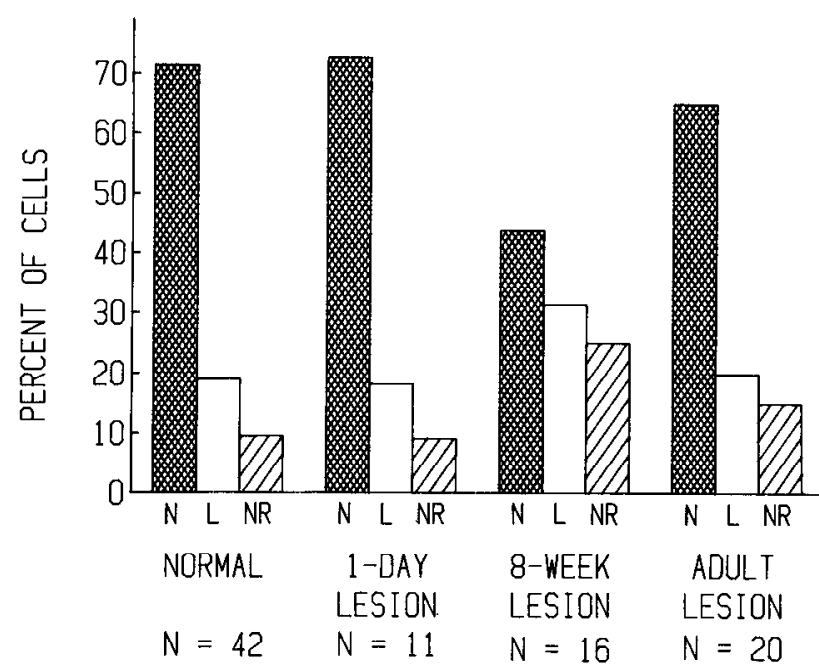

Figure 4. Linearity of spatial summation for LGN cells in the A-layers (top) and C-layers (bottom) of normal cats and cats with a visual cortex lesion at different ages. $N$, cells that showed nonlinear spatial summation and response doubling (a temporal nonlinearity) to a counterphased grating; $L$, cells that had linear spatial summation; $N R$, cells that failed to respond to the counterphased grating at any spatial location. Number of cells for which linearity was tested is given below each condition.

ed optimally to 1 or 2 of the spatial frequencies tested and gave a decreased response to higher spatial frequencies. In addition, many cells had a decreased response to spatial frequencies lower than the optimum; that is, a low-frequency roll-off was present in the spatial-frequency response function. The general form of these functions was similar for normal LGN cells and surviving LGN cells in all 3 lesion groups.

With few exceptions, individual cells responded with both an increase in average discharge (F0) and with a discharge modulated at the fundamental frequency of the drifting grating (F1), and the spatial-frequency response functions were similar for the $\mathrm{F} 0$ and $\mathrm{F} 1$ responses. In addition, results of between-group comparisons were the same whether data for $F 0$ or $F 1$ responses 
A LAYERS
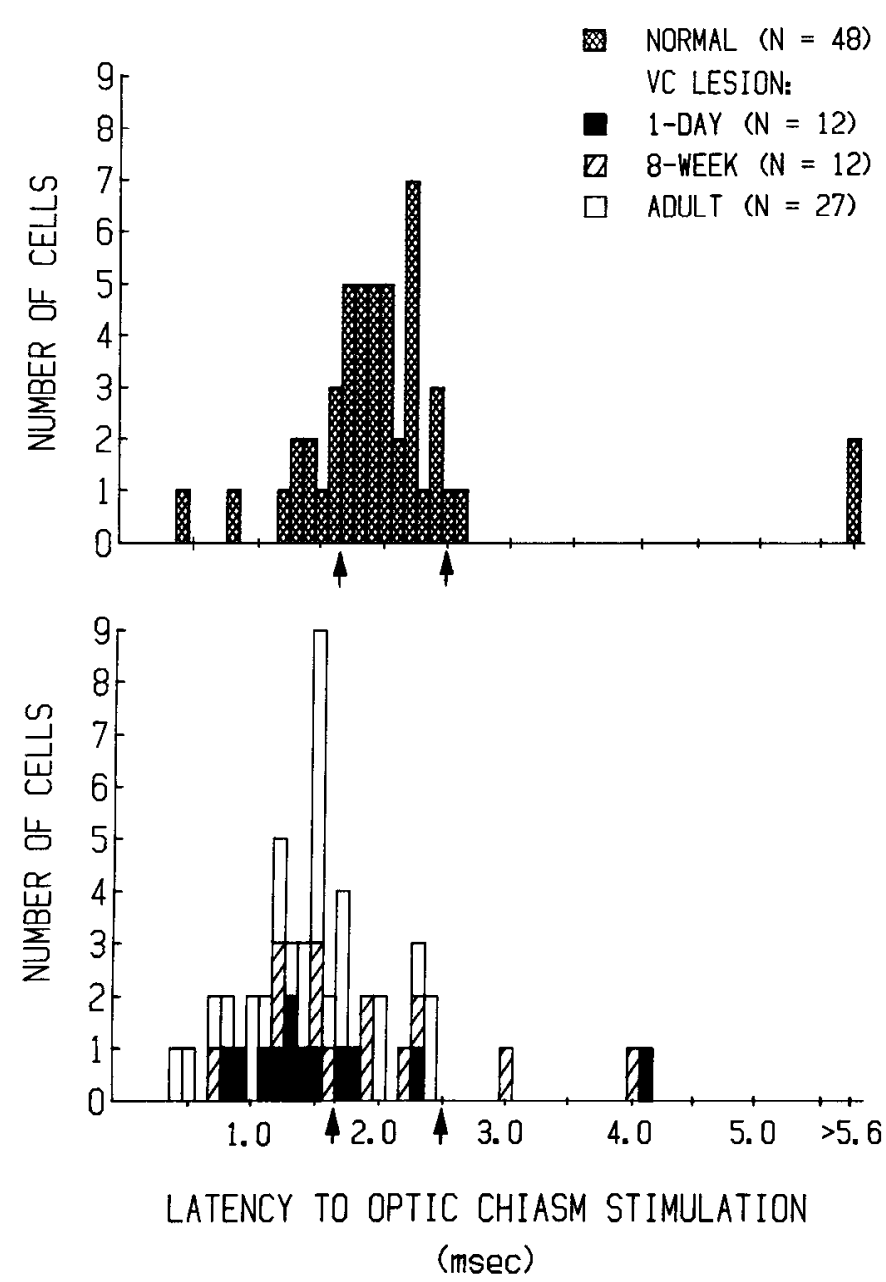

C LAYERS
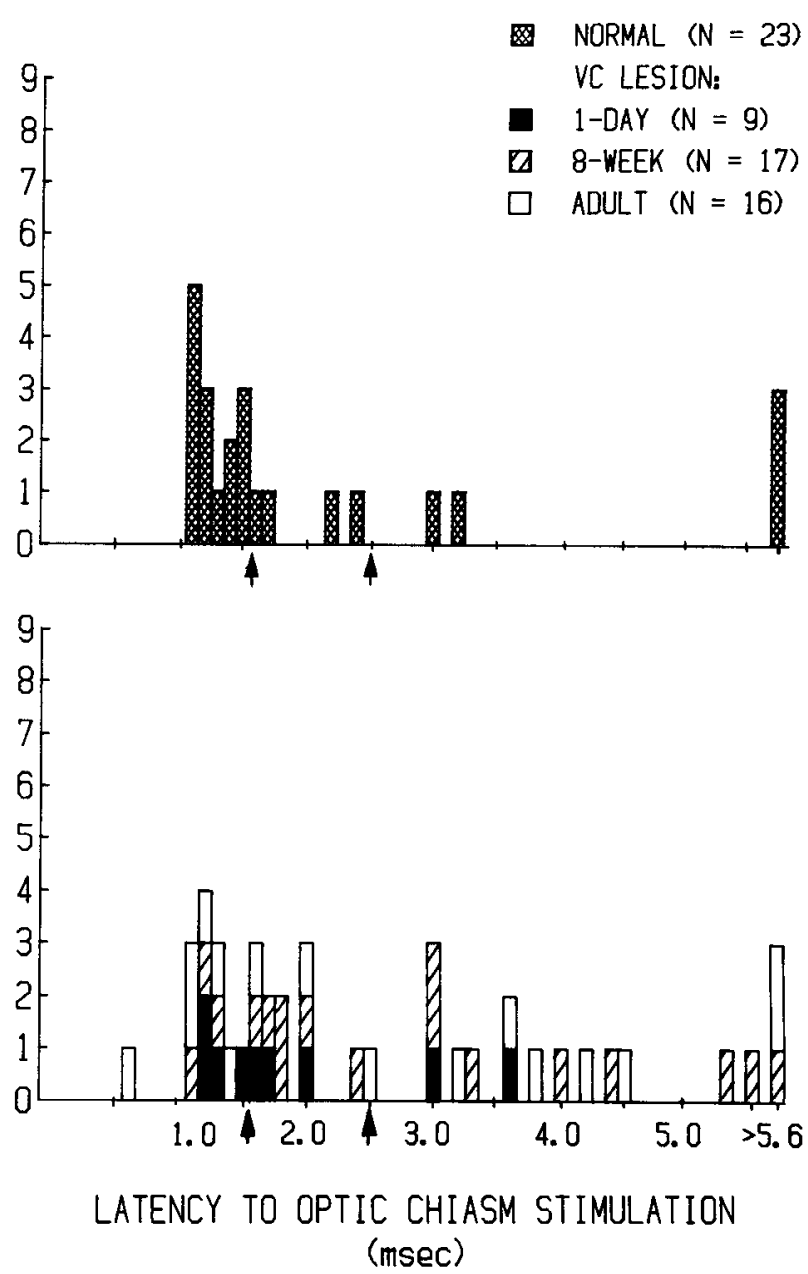

Figure 5. Modal response latency for cells that responded to OX stimulation. Data are presented separately for cells recorded in the A-layers (A and $\mathrm{A} 1$ combined; left $)$ and $\mathrm{C}$-layers $(\mathrm{C}, \mathrm{Cl}$, and $\mathrm{C} 2$ combined; right). Results for normal animals are shown at the top, and results for surviving cells in the degenerated LGN of animals with a visual cortex lesion at different ages are shown at the bottom. Arrows along the abscissas indicate latencies of 1.6 and $2.5 \mathrm{msec} . N$, number of responsive cells in each condition.

were used. Therefore, only results for the F1 response are presented below.

Spatial resolution. The distributions of spatial resolutions for the fundamental responses to drifting gratings are shown in Figure 8. In the A-layers of normal cats, most cells had spatial resolutions of $0.8 \mathrm{c} / \mathrm{deg}$ or higher. In contrast, most surviving A-layer cells in cats with a visual cortex lesion had spatial resolutions below $0.8 \mathrm{c} / \mathrm{deg}$ (Fig. 8 , left). There was no difference in the spatial resolutions among the 3 lesion groups, and together these groups had significantly lower spatial resolutions than normal ( $t$ test, $p<0.01$ ). The results were the same when cells with receptive fields between area centralis and an eccentricity of $20^{\circ}$ were analyzed separately.

In normal cats, $X$ cells tend to have the highest spatial resolution to drifting gratings (Derrington and Fuchs, 1979; So and Shapley, 1979; Lehmkuhle et al., 1980; Troy, 1983). Therefore, it is possible that the overall reduction in spatial resolution in degenerated LGNs is due to the loss of X cells and not to an abnormality among surviving cells. To test this possibility, spatial resolutions were compared for normal $\mathrm{Y}$-cells and surviving $\mathrm{Y}$-cells in the degenerated LGNs (see Fig. 10, left). There was no significant difference between these 2 samples. However, spatial resolution was tested for only a small sample of $Y$ cells in the normal A-layers, and it is possible that a larger sample would reveal a significant difference.

Spatial resolutions of normal C-layer cells tend to be lower than those of normal A-layer cells, primarily because $\mathrm{X}$ cells rarely are encountered in the $C$-layers. There was no significant difference between the 3 lesion groups and normals (Fig. 8, right).

Optimal spatial frequency. Figure 9 shows the optimal spatial frequencies for the fundamental responses to drifting gratings. There were no significant differences among the 3 lesion groups for optimal spatial frequencies of surviving A-layer cells (Fig. 9 , left). Together these surviving cells had significantly lower optima than normal A-layer cells ( $t$ test, $p<0.01$ ). When only $Y$ cells were compared, however, there was no significant difference between normal and surviving LGN cells (Fig. 10, right). In the $\mathrm{C}$ layers, optimal spatial frequencies were similar among all 4 groups (Fig. 9, right).

Response amplitude. Response amplitude was determined for each cell by subtracting the spontaneous activity of the cell 
during presentation of a blank screen from the response to the optimal spatial frequency (i.e., the maximum response). Levels of spontaneous activity were similar among LGN cells in normal cats and cats with a visual cortex lesion.

The mean $( \pm \mathrm{SE})$ maximum fundamental response was 25.2 $( \pm 2.0)$ spikes/sec for all normal A-layer cells (21.1 \pm 4.2 spikes/ sec for normal A-layer Y cells). Similar values were obtained for surviving A-layer cells in all 3 groups with a visual cortcx lesion $(21.7 \pm 2.7 \mathrm{spikes} / \mathrm{sec}$ for all cells in all groups combined).

In normal $C$ layers, the maximum fundamental response was $27.0( \pm 4.3)$ spikes/sec. The variability among cells in the normal C-layers was greater than in the normal A-layers because the C-layer sample included Y cells, which have brisk responses, and $\mathrm{W}$ cells, which tend to have sluggish responses. Similar response amplitudes were seen for surviving C-layer cells in degenerated LGNs $(18.2 \pm 2.4$ spikes/sec for all cells in all groups combined).

In general, the amplitudes of the average response rates (F0) were slightly lower than the Fl responses; however, the betweengroup response-amplitude relationships were the same.

\section{Spatial resolution to counterphased gratings}

Figure 11 shows the spatial resolutions of the second-harmonic (F2) responses to counterphased gratings for cells that had nonlinear spatial summation. Because only a small number of cells was tested in each of the lesion groups, results from these groups were combined for statistical comparison with normal cells. For both the A- and C-layers, there were no significant differences between $F 2$ spatial resolutions for normal cells and cells in the degenerated LGN of cats with a visual cortex lesion.

\section{Area-response functions}

Area-response functions were determined for 26 cells in normal A-layers and 25 surviving cells in degenerated A-layers from the 3 lesion groups (6 from KVC-1D, 2 from KVC-8WK, 17 from AVC). In the C-layers, area-response functions were determined for 23 normal cells and 19 surviving LGN cells in cats with a visual cortex lesion ( 3 from KVC-1D, 9 from KVC- 8 WK, 7 from AVC). Because the samples were so small from each lesion group, they were combined for statistical comparisons with normals.

Optimal stimulus size. The mean optimal spot diameter for all normal A-layer cells was $2.7^{\circ}\left( \pm 0.36^{\circ} \mathrm{SE}\right)$. Cells in the degenerated A-layers had a mean optimal spot diameter of $6.3^{\circ}$ $\left( \pm 1.0^{\circ}\right)$, which is significantly larger than normal ( $t$ test, $p<$ 0.01 ). This result is in accord with the observation that receptive-field center size of cells in degenerated A-layers is larger than normal when all cells are compared. When only $Y$ cells are considered, the optimal stimulus size for surviving A-layer cells $\left(6.1^{\circ} \pm 1.1^{\circ}, n=18\right)$ was still somewhat larger than normal $\left(4.8^{\circ} \pm 0.76^{\circ}, n=7\right)$, although the difference is not statistically significant. For C-layer cells, optimal spot diameter for LGN cells $\left(5.2^{\circ} \pm 0.96^{\circ}\right)$ also was slightly larger than normal $\left(4.2^{\circ} \pm\right.$ $0.73^{\circ}$ ), although the difference was not statistically signficant.

Strength of surround inhibition. As a group, surviving cells in degenerated A-layers had significantly weaker surround inhibition than normal A-layer cells ( $t$ test, $p<0.01$, Fig. 12, left). Because $X$ cells tend to have stronger surround inhibition than Y cells (Bullier and Norton, 1979; Kaplan et al., 1979; So and Shapley, 1981), this difference could be due to the loss of $\mathrm{X}$ cells from degenerated layers rather than to an abnormality among surviving cells. Comparisons of just the $\mathrm{Y}$ cells revealed no
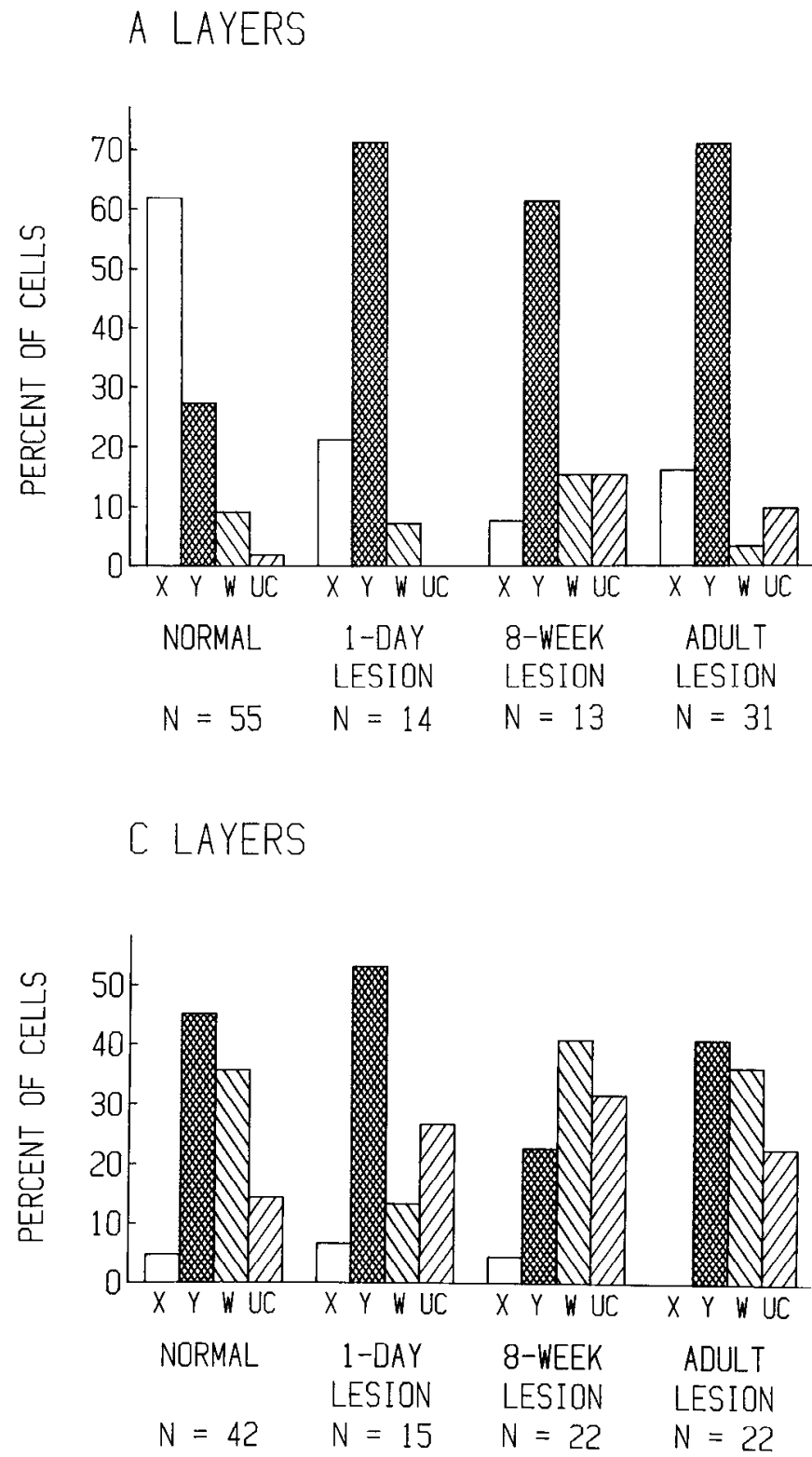

Figure 6. Percentages of cells encountered that were classified as $\mathrm{X}$ $\mathrm{Y}$, or $\mathrm{W}$. Cells that had mixed properties or that responded too poorly to be classified with confidence were considered as unclassified (UC) Cells for which insufficient data were obtained on the classifying tests were excluded from the analysis. Top, Results for layers $\mathrm{A}$ and $\mathrm{Al}$ combined; bottom, results for all C-layers combined. $N$, number of cells in each condition.

significant difference in surround strength for cells in normal (mean decrease $46 \pm 3.8 \%, n=7$ ) and degenerated LGNs (mean decrease $32 \pm 4.7 \%, n=18$ ). In the C-layers, there also was no significant difference in the strength of surround inhibition for normal cells and cells that survived after a visual cortex lesion (Fig. 12, right).

Peak response to spots. Peak response rate was determined for each cell using the optimal spot size for that cell. For A-layer cells, mean peak response rate was $74.6( \pm 9.4)$ spikes/sec for all cells $(61.0 \pm 20.1$ spikes/sec for $Y$ cells alone $)$. Peak response rates for degenerated LGN cells were not significantly different from normal ( $53.1 \pm 8.9$ spikes/sec for all cells). Peak response rates also were not significantly different for C-layer cells in 

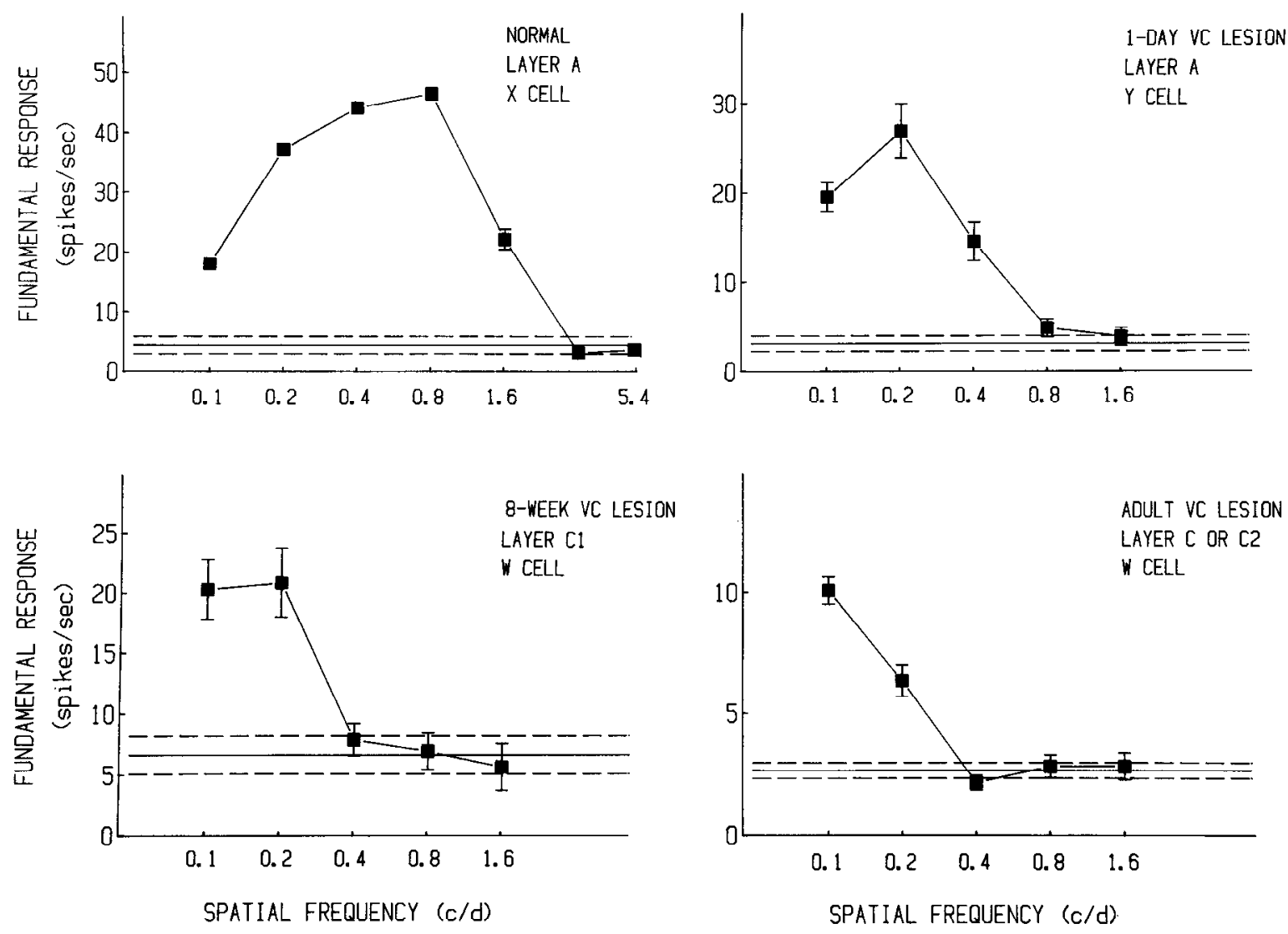

Figure 7. Examples of spatial-frequency response functions to $3 \mathrm{~Hz}$ drifting sine-wave gratings for neurons in normal and degenerated LGNs. Each point in the curves represents the mean, and brackets represent \pm 1 SE of the fundamental response (F1) to repeated presentations of the spatial frequency indicted on the abscissa. The horizontal solid and dashed lines indicate the mean $\pm 1 \mathrm{SE}$ of the inherent $3 \mathrm{~Hz}$ activity (F1) of the cell during repeated presentations of a blank screen.

normal $(94.2 \pm 11.5 \mathrm{spikes} / \mathrm{sec})$ and degenerated $(60.3 \pm 8.3$ spikes/sec) LGNs.

\section{Response to the nondominant eye}

Nearly all responsive cells in all 4 groups were driven strongly by only one eye (the dominant eye). Only 2 cells in normal cats and 3 in AVC cats gave a weak excitatory response to the other (nondominant) eye that could be detected on the audio monitor (all were in the C-layers). However, quantitative measures revealed that many cells were influenced by the nondominant eye.

In the normal A-layers, $60 \%$ of 25 cells that were tested had a statistically significant $\mathrm{F} 0$ and/or F1 response to stimulating the nondominant eye with a drifting grating. Both excitatory and inhibitory responses were seen, in agreement with a more extensive study of nondominant eye responses to drifting gratings in normal adult LGN (Guido et al., 1989). In the degenerated A-layers, 26 cells were tested (6 from KVC-1D, 4 from $\mathrm{KVC}-8 \mathrm{WK}, 16$ from $\mathrm{AVC}$ ), of which $46 \%$ showed a significant response. Figure 13 (top) shows the direction (excitatory or inhibitory) and magnitude of the F0 responses for both groups. The proportion of responsive cells that had an inhibitory F0 response was higher in degenerated A-layers ( 8 of 9 responsive cells) than in normal A-layers ( 5 of 12 responsive cells; Fisher's exact probability, $p=0.035$, 2-tailed). However, the samples were small, and this difference should be viewed with caution. Among responsive cells, the magnitudes of inhibitory responses to the nondominant eye were similar for the 2 groups.

In the normal C-layers, $45 \%$ of 29 cells that were tested showed a significant response to the nondominant eye. Among 27 cells ( 5 from KVC-1D, 9 from KVC-8WK, 13 from AVC) tested in degenerated $\mathrm{C}$-layers, $44 \%$ responded. The percentages of cells showing excitation or inhibition to the nondominant eye, and the magnitude of the responses, were similar for the 2 groups (Fig. 13, bottom).

\section{Discussion}

Potential limitations of the present study

Several potential limitations must be considered when interpreting the results of this study. First, in order to collect comparable proportions of cells in the A- and C-layers in all groups, we often collected data for only a few cells in each microelectrode penetration through layers $A$ and $A 1$ of the normal cats. Because the properties of A-layer cells vary somewhat with depth in the layer (Mitzdorf and Singer, 1977; Bowling and Wieniawa-Narkiewicz, 1986, 1987), these samples may not be sufficiently random to be representative of A-layer cells in normal cats. However, both the qualitative and quantitative results for normal A-layer cclls in our sample are similar to those of other studies in which the A-layer sampling was more complete (e.g., Derrington and Fuchs, 1979; So and Shapley, 1979; Lehmkuhle et al., 1980; Spear et al., 1982; Troy, 1983; Crabtree et al., 1986; McCall et al., 1987). Therefore, our A-layer sample does seem to be representative.

Second, the total number of cells recorded in the degenerated LGN for each age group is relatively small. As a result, we may have failed to detect small differences between age groups or 

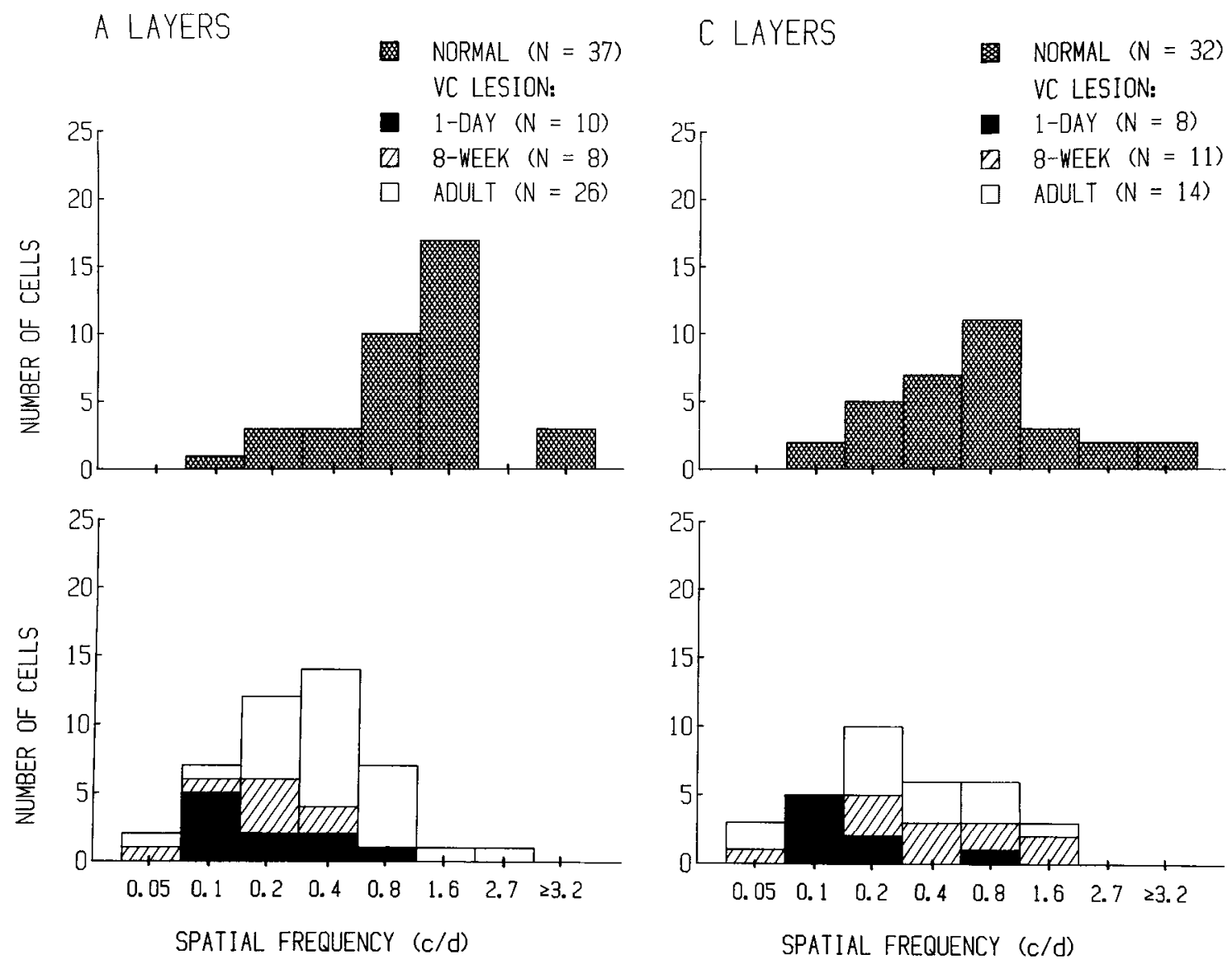

Figure 8. Spatial resolutions of LGN cells in normal cats (top) and cats with a visual cortex lesion (bottom). Results are based on responses at the fundamental frequency of the $3 \mathrm{~Hz}$ drifting sine-wave gratings. Conventions as in Figure 5.

between degenerated and normal LGNs. Indeed, for several comparisons there was a tendency for properties of surviving LGN cells to differ from those of normal LGN cells, but the differences did not reach statistical significance. It is quite possible that these differences would be found to be statistically reliable with larger samples. However, our results suggest that, even if statistically significant, such differences are likely to be small. Furthermore, when abnormalities were observed in animals with a visual cortex lesion, the between-group differences were large and statistically robust, and we feel confident that they are reliable.

A final concern, relevant to any study of abnormal development, is whether it is appropriate to use normal criteria to classify potentially abnormal cells. We took 2 precautions because of this concern. First, we present the data separately for each response property so that the results can be evaluated independent of presumptive cell classes. Second, when classifying cells as $\mathrm{X}, \mathrm{Y}$, or $\mathrm{W}$, we did not use properties that were likely to be unreliable or inappropriate to abnormal cells. For instance, we did not use "sluggishness" of response (a characteristic of normal W cells) because it is possible that cells with altered inputs respond sluggishly, regardless of class. We also did not use layer location in classifying cells because shrinkage and distortion of the degenerated LGN could alter the locations of cell classes and because retinal $\mathrm{X}, \mathrm{Y}$, and $\mathrm{W}$ inputs might project to inappropriate layers after a visual cortex lesion.

Even though we avoided some commonly used criteria for classifying cells, our results in normal cats were similar to those reported elsewhere. Layers $\mathrm{A}$ and A1 contained almost exclusively $\mathrm{X}$ and $\mathrm{Y}$ cells, and the percentages were similar to those found in other studies (e.g., Hoffmann et al., 1972; Cleland et al., 1976; Wilson et al., 1976; Spear et al., 1982; Friedlander and Stanford, 1984; Crabtree et al., 1986; McCall et al., 1987). A few cells were classified as $\mathrm{W}$ in the normal A-layers, which is somewhat atypical. However, normal A-layer cells with W-like responses and with slowly conducting axons have been reported previously (Cleland et al., 1976). We found that normal layer $C$ contained $Y$ and $W$ cells and very few $X$ cells, and layers $\mathrm{C} 1$ and $\mathrm{C} 2$ contained almost exclusively $\mathrm{W}$ cells, as reported by others (Cleland et al., 1976; Wilson et al., 1976; Mitzdorf and Singer, 1977; Sur and Sherman, 1982; Stanford et al., 1983; Frascella and Lehmkuhle, 1984; Spear et al., 1989). Thus, the results in normal cats suggest that the criteria were valid for identifying $\mathrm{X}, \mathrm{Y}$, and $\mathrm{W}$ cells.

\section{Response properties of surviving $L G N$ cells}

We found that surviving cells in both the $A$ and $C$ layers of the LGN respond to light after either an early ( $1 \mathrm{~d}$ or 8 weeks) or adult visual cortex lesion. This confirms and extends the results of Murphy and Kalil (1979), who recorded from 30 surviving LGN cells (layer location was not determined) in cats that had received a visual cortex lesion on the day of birth, and of Chow and Lindsley (1969), who recorded from 19 LGN cells (18 in the A-layers and 1 in the C-layers) in cats that had received a visual cortex lesion as adults.

Although the cells respond to light, we observed 2 clear ab- 
A LAYERS
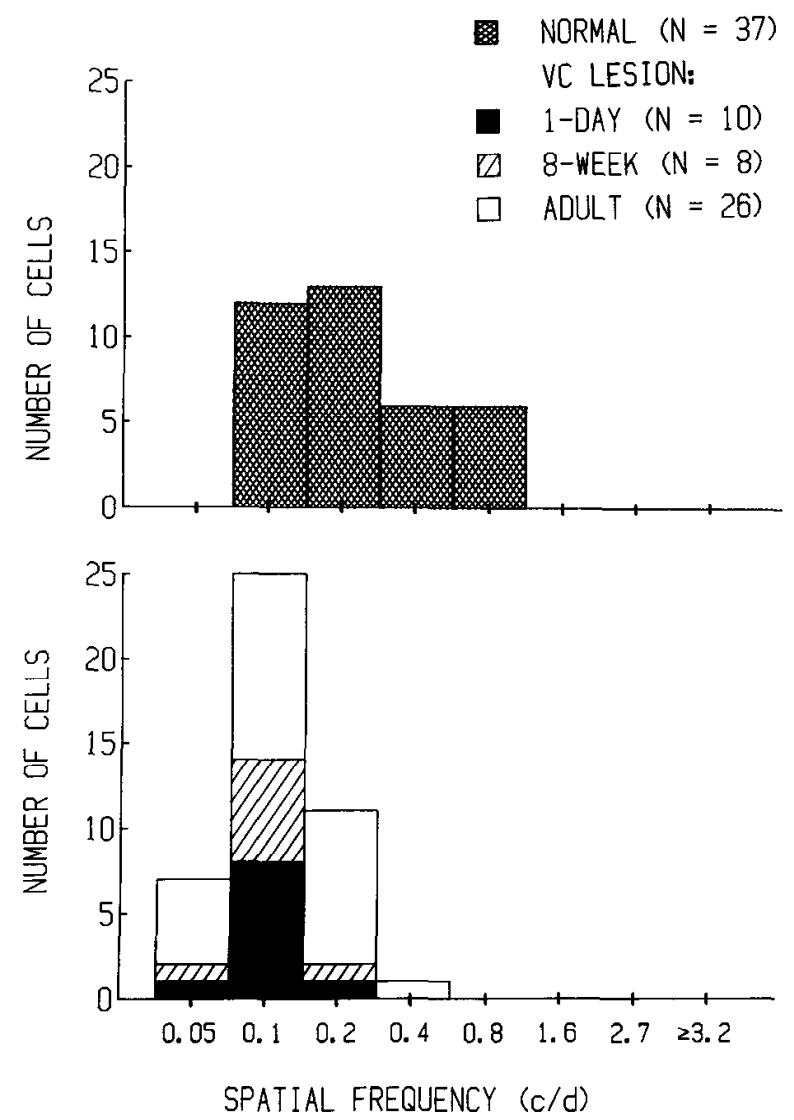

\section{LAYERS}
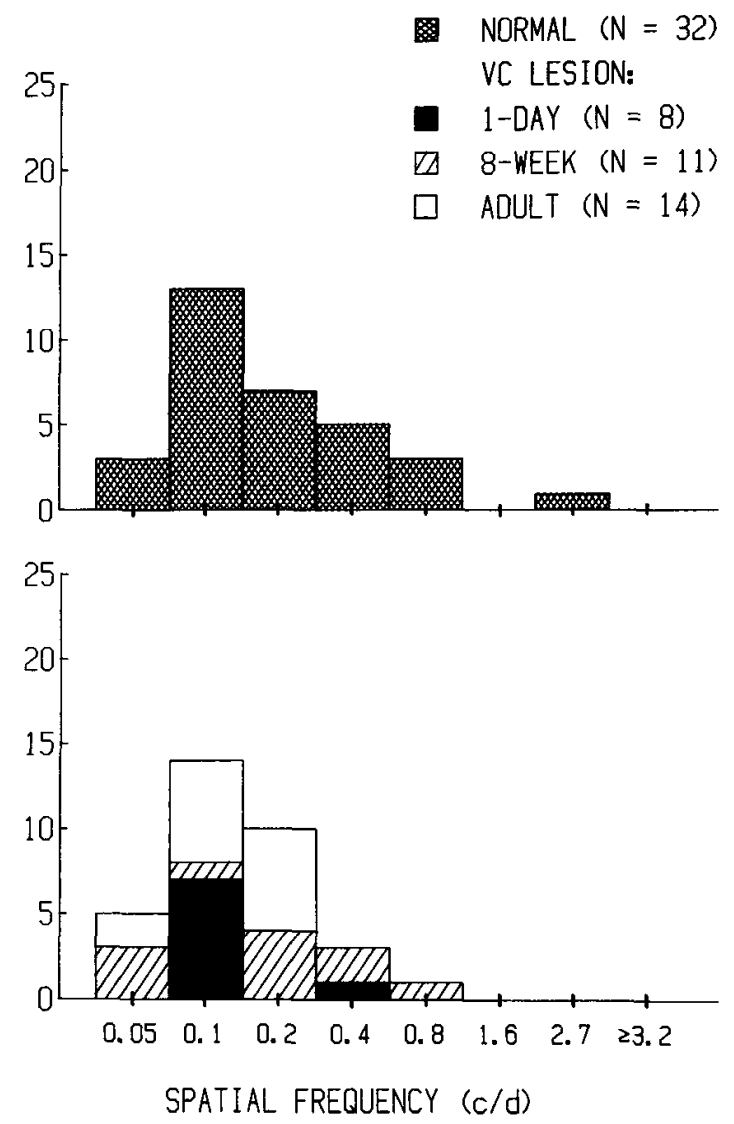

Figure 9. Optimal spatial frequencies of the fundamental responses to $3 \mathrm{~Hz}$ drifting sine-wave gratings. Conventions as in Figure 5.

Figure 10. Left. Spatial resolutions of the fundamental responses to $3 \mathrm{~Hz}$ drifting sine-wave gratings for A-layer $Y$-cells in normal cats $(t o p)$ and surviving A-layer $\mathrm{Y}$-cells in cats with a visual cortex lesion (bottom). Data from all 3 lesion groups are combined. Right. Optimal spatial frequencies for the same samples of cells.
SPATIAL RESOLUTION
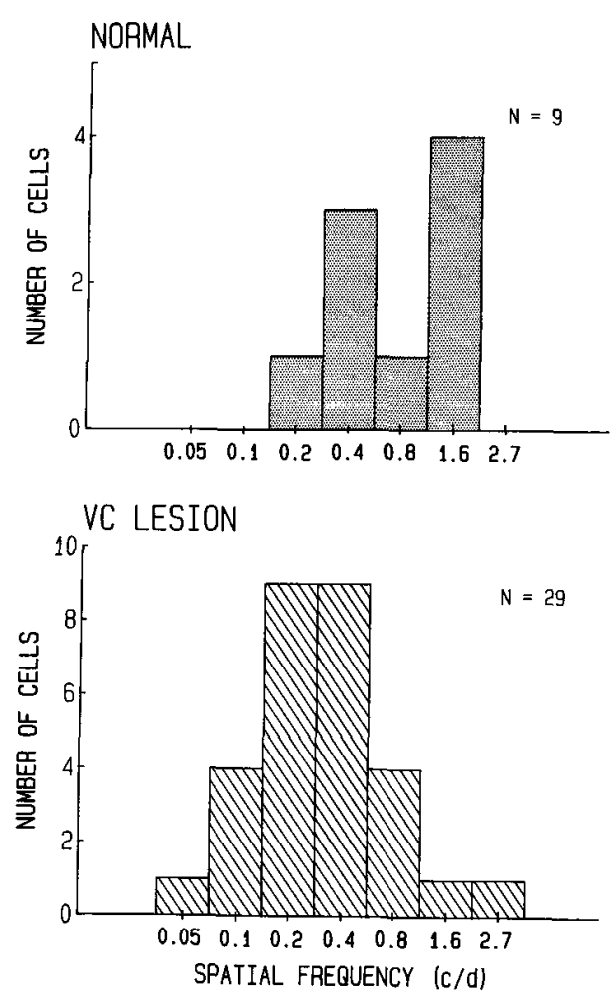

OPTIMAL SPATIAL FREQUENCY
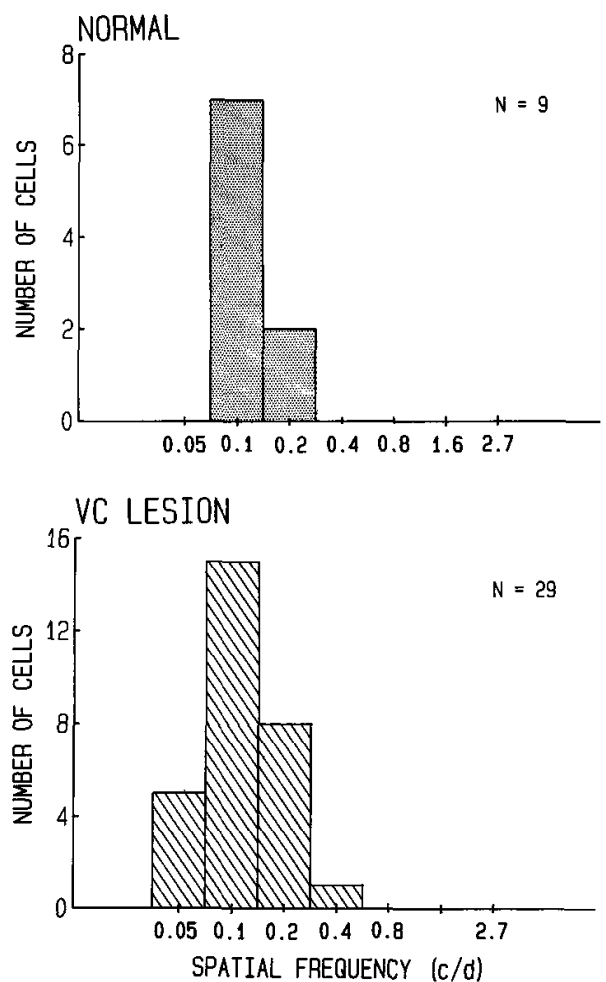

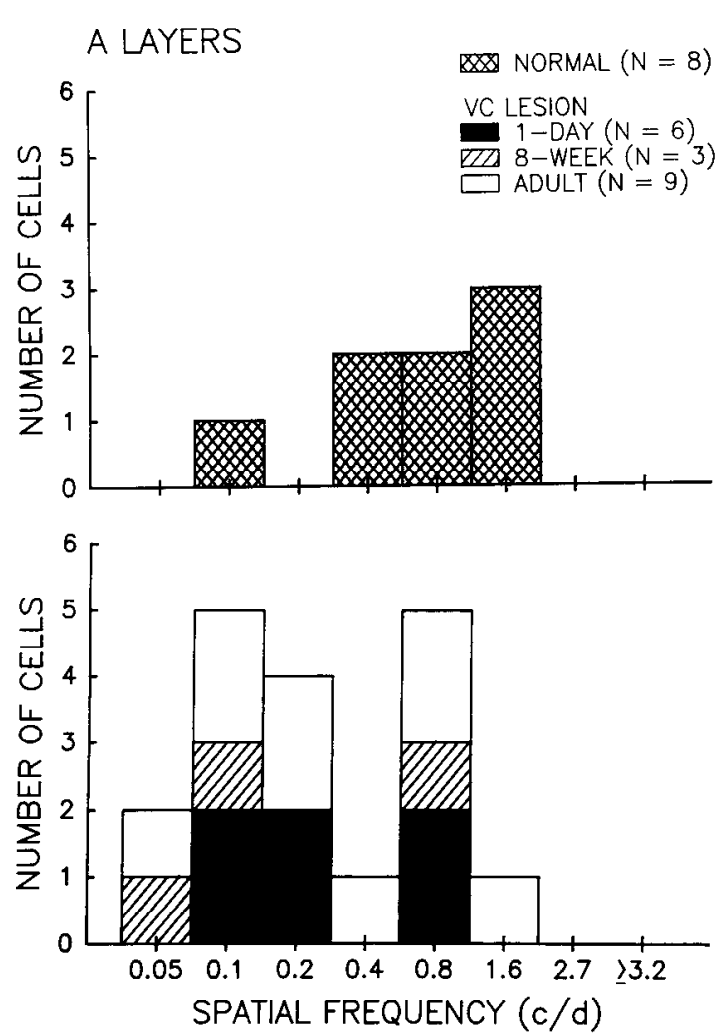

C LAYERS
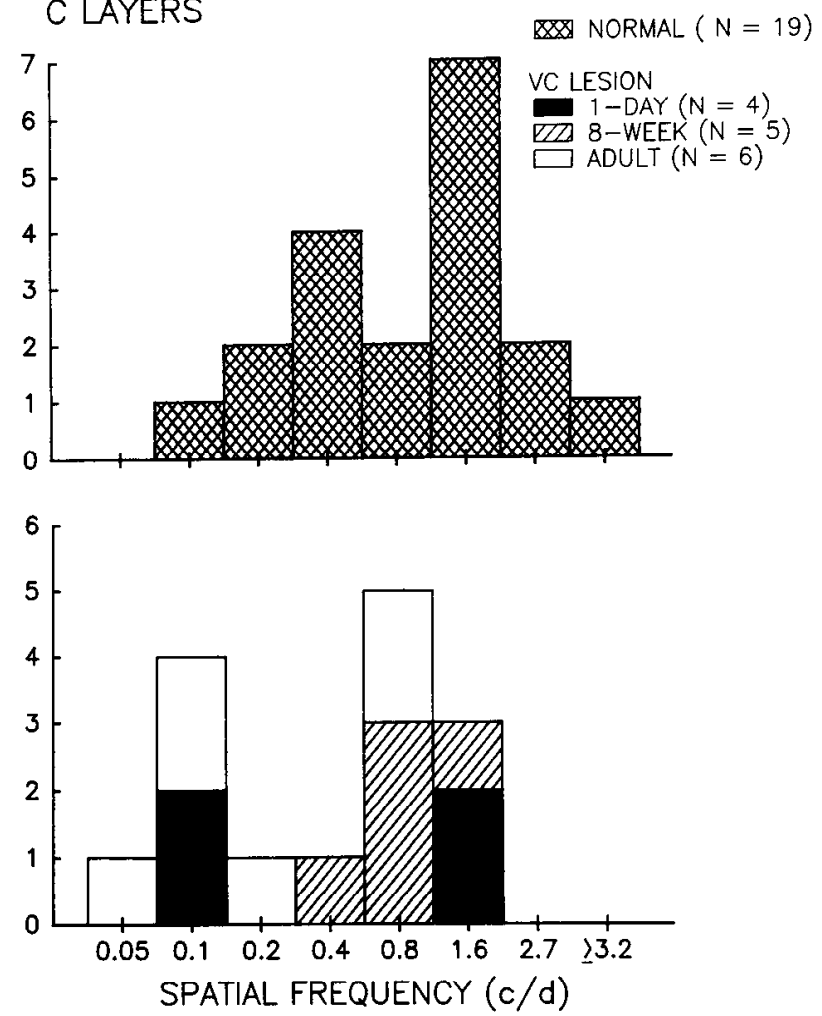

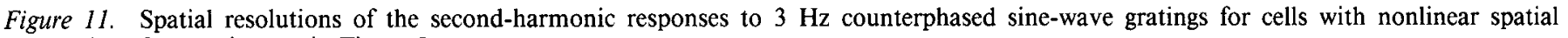
summation. Conventions as in Figure 5.

normalities in the degenerated LGN following a visual cortex lesion at all 3 ages tested. First, there is a reduction in the proportion of $\mathrm{X}$ cells recorded in the A-layers. This reduction is observed with each of the criteria used to classify cells. Thus, the visual cortex lesion appears to produce a loss of cells with a variety of related response properties, not just an abnormality in a single response property used to classify cells. In a recent abstract, Sur et al. (1987b) reported that a reduction in LGN X cells also occurs after a visual cortex lesion in newborn ferrets.

We cannot rule out the possibility that, in addition to the $\mathrm{X}$ cell loss, there is a proportionately smaller loss of A-layer $Y$ cells after a visual cortex lesion. To address this possibility it is necessary to know the absolute numbers of $\mathrm{X}$ and $\mathrm{Y}$ cells in both normal and degenerated A-layers and the percentage of A-layer neurons that degenerate after a visual cortex lesion at each age. Unfortunately, this information is not available. However, Chow and Dewson (1966) found that about 70\% of LGN neurons in all layers (not just $\mathrm{A}$ and $\mathrm{Al}$ ) degenerate after longterm visual cortex damage in adult cats, and Weber and Kalil (unpublished observations) have estimated that about $80 \%$ of A-layer neurons degenerate after a visual cortex lesion in newborn kittens. If about $65 \%$ of A-layer neurons are $\mathrm{X}$ cells in normal cats (Friedlander et al., 1981; Friedlander and Stanford, 1984), then it is conceivable that the loss of A-layer LGN cells is fairly selective to $\mathrm{X}$ cells.

In the C-layers, we recorded normal proportions of $\mathrm{W}$ and $\mathrm{Y}$ cells following a visual cortex lesion at all 3 ages. Measures of cell density and LGN volume indicate that cellular degeneration in the C-layers is less severe than in the A-layers after a neonatal visual cortex lesion (Weber and Kalil, unpublished observations); however, the extent of the C-layer cell loss (if any) has not been quantified after a lesion at any age. Therefore, we cannot determine whether $\mathrm{C}$-layer $\mathrm{W}$ and $\mathrm{Y}$ cells actually are present in normal numbers or whether both types are reduced in equal proportions.

Whether or not there is some loss of $\mathrm{Y}$ and $\mathrm{W}$ cells, it seems clear that the major effect of the visual cortex lesion at all 3 ages is a disproportionate reduction in $\mathrm{X}$ cells encountered in layers $A$ and A1. What is the fate of the X cells? One possibility is that they are still present but have shrunken and could not be sampled by our microelectrodes. Another possibility is that retinal inputs have switched so that cells that normally would be $X$ cells now receive $Y$ cell inputs and respond as $Y$ cells. However, in view of the severe anatomical loss of neurons that occurs in the LGN after a visual cortex lesion (Chow and Dewson, 1966; Weber and Kalil, unpublished observations), it seems likely that the $\mathrm{X}$ cells have degenerated and died.

The second abnormality that occurs after a visual cortex lesion is that many surviving LGN cells have abnormally large receptive-field centers. This result has been reported previously for cats that received a visual cortex lesion on the day of birth (Murphy and Kalil, 1979). The present results extend those findings by showing that both $\mathrm{A}$ - and C-layer cells have abnormally large receptive fields following both early ( $1 \mathrm{~d}$ and 8 weeks) and adult visual cortex damage.

A number of other differences were observed between normal A-layer cells and A-layer cells that survive after a visual cortex lesion. Lesioned cats have fewer A-layer cells with very small receptive-field centers, with intermediate latencies to OX stimulation, and with linear spatial summation. In addition, there is a decrease in average spatial resolution and optimal spatial frequency and a decrease in strength of surround inhibition 
A LAYERS

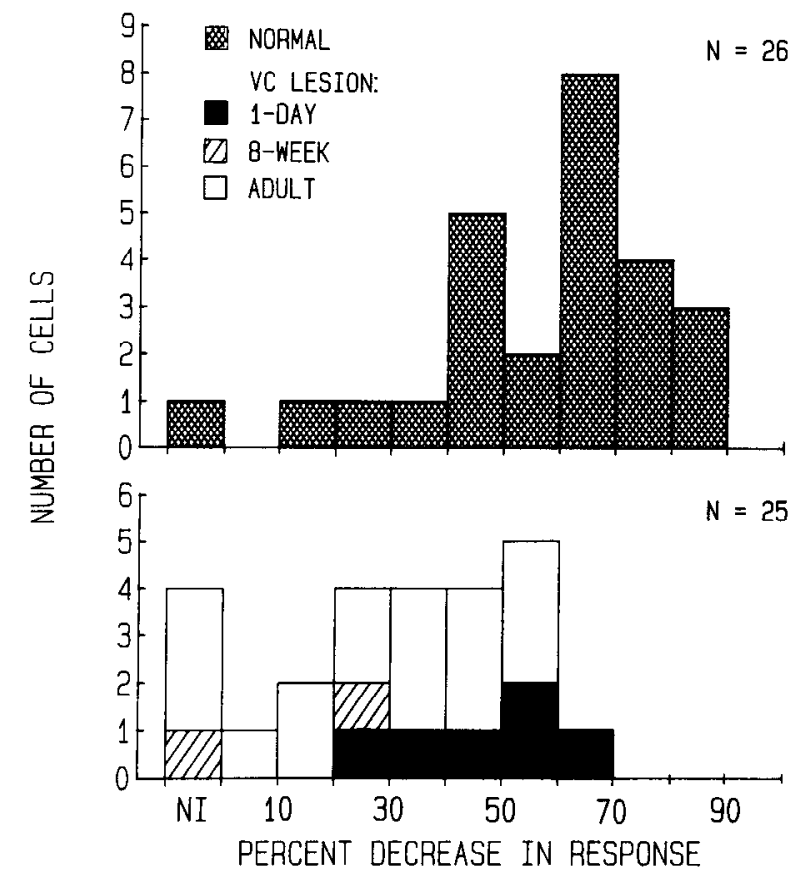

C LAYERS
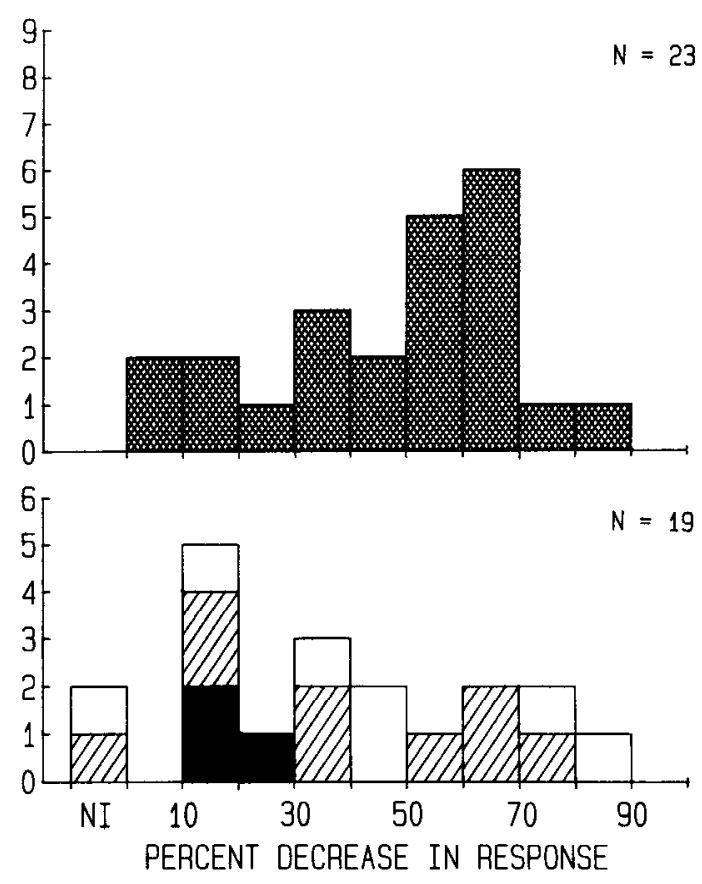

Figure 12. Strength of surround inhibition determined from area-response functions. The abscissa gives the percentage decrease in peak response rate to the largest spot tested (generally $10^{\circ}$ diameter) compared with the optimal spot for that cell. NI. no inhibitory surround detected. Conventions as in Figure 5.

among the remaining A-layer cells. All of these differences can be attributed to the loss of $X$ cells from the A-layers. When surviving A-layer $Y$ cells are compared with normal $Y$ cells, or when surviving $\mathrm{C}$-layer $\mathrm{W}$ and $\mathrm{Y}$ cells are compared with normal C-layer cells, all of these properties appear relatively normal. In addition, the spatial resolution of the second-harmonic response to counterphased gratings is relatively normal, as are response amplitudes to flashed spots and drifting sine-wave gratings.

We also found that surviving LGN cells have normal receptive-field organization (e.g., center-surround concentric receptive fields for A-layer cells), in agreement with previous studies (Chow and Lindsley, 1969; Murphy and Kalil, 1979). In addition, nearly all surviving cells are monocularly driven, and the normal alternation of layers driven by the contra- or ipsilateral eye is maintained, regardless of the cat's age at the time of the lesion. Murphy and Kalil (1979) also found normal monocular responsiveness in their cats with a lesion on the day of birth. However, Chow and Lindsley (1969) reported an increase in the percentage of binocular LGN cells, from $3 \%$ (5 of 145 cells) in normal cats to $40 \%$ ( 8 of 19 ) in cats that received a visual cortex lesion as adults. Although we recorded from a somewhat larger sample of surviving LGN cells in AVC cats than did Chow and Lindsley (61 vs 19 ), it is possible that the difference in results is a consequence of the relatively small size of both samples.

We found that the gross retinotopic organization is normal in the degenerated LGN following a visual cortex lesion at all 3 ages tested, which confirms and extends Murphy and Kalil's (1979) observations in animals that received a visual cortex lesion at birth. Murphy and Kalil (1979) also reported that small changes in recording location often resulted in abnormally large and erratic shifts in receptive-field location, and they concluded that the fine-grain retinotopic organization is abnormal in the degenerated LGN. Although we also encountered shifts in receptive-field location as the microelectrode traversed the degenerated LGN, the shifts did not appear to be abnormal. In normal cats, some change in receptive-field location often occurs between layers, and there is a relatively large receptive-field scatter within the C-layers (Bishop et al., 1962b; Bishop, 1965; Sanderson, 1971a, b; see Fig. 2, bottom). Furthermore, because the degenerated LGN is much smaller than normal, neighboring LGN cells would be expected to have more distant receptivefield centers than normal; i.e., the topographic map should be compressed. When these factors are taken into account, we found that the retinotopic organization of the degenerated LGN is relatively normal following a lesion at each age tested (e.g., Fig. 2, top). However, neither we nor Murphy and Kalil (1979) undertook a detailed analysis of retinotopic organization, and a more thorough analysis is required to determine if visual topography is completely normal.

Perhaps the most surprising finding is that there is no obvious difference in the response properties of surviving LGN neurons among cats that received a visual cortex lesion on the day of birth, at 8 weeks of age, or as adults. If there are differences among these conditions, larger samples or other tests are necessary to reveal them.

\section{Relationship of results to retinal inputs}

Anatomical and physiological studies indicate that from 60 to $90 \%$ of retinal X cells are lost following removal of the visual cortex within a few days of birth (Table 1, row 1) (Pearson et al., 1981; Tong et al., 1982; Callahan et al., 1984; Kalil, 1984; 
Payne et al., 1984), and this corresponds with the $66 \%$ loss of A-layer X cells in KVC-1D cats. However, when visual cortex is removed at 4 weeks of age or later, only $20 \%$ or fewer retinal $\mathrm{X}$ cells are lost (Table 1, row 1) (Callahan et al., 1984; Kalil, 1984), whereas 87 and $74 \%$ of A-layer X cells are lost in KVC$8 \mathrm{WK}$ and $\mathrm{AVC}$ cats. One explanation for this difference between retina and $L G N$ is that the retinal $X$ cells continue to project to the LGN in KVC-8WK and AVC cats but fail to drive surviving LGN cells. An alternative possibility is that the retinal $\mathrm{X}$ cells project elsewhere in the brain in KVC-8WK and AVC cats. This possibility is supported by the observation that many, and perhaps all, adult retinogeniculate $X$ cell axons have a collateral branch that projects toward the midbrain (Bowling and Michael, 1984; Sur et al., 1987a). These collaterals could sustain the retinal $X$ cells in older animals even though the $X$ cells no longer connect with $\mathrm{LGN}$ target neurons. If retinal $\mathrm{X}$ cells in young kittens have not yet developed collateral projections to the midbrain, it would explain why retinal $\mathrm{X}$ cells are lost after a visual cortex lesion in KVC-1D animals. A question that remains, however, is why retinal $\mathrm{X}$ cell axons in $\mathrm{KVC}-8 \mathrm{WK}$ and AVC cats fail to connect to or drive LGN cells while retinal $\mathrm{Y}$ and $\mathrm{W}$ cell axons in the same animals succeed in maintaining functional connections in the LGN.

The presence of a relatively normal retinotopic map, normal layer organization of eye dominance, and normal layer location of $Y$ and $W$ cells in the LGN indicates that the retinogeniculate $\mathrm{Y}$ and $\mathrm{W}$ cell axons project to the correct location in the LGN following a visual cortex lesion at each age tested. Indeed, the presence of normal $\mathrm{Y}$ and $\mathrm{W}$ cells in the LGN indicates that the $\mathrm{Y}$ and $\mathrm{W}$ retinal axons maintain (or develop) their normally separate and parallel connections to individual LGN cells despite the visual cortex lesion. On the other hand, the abnormally large receptive fields among surviving IGN cells suggests that the terminal axon spread and resulting retinogeniculate convergence patterns are abnormal, a suggestion that agrees with anatomical studies (Kalil, 1978, 1984; Weber et al., 1986; Kalil and Behan, 1987). The observation that LGN cells with abnormally large receptive-field centers have normal spatial resolutions and optimal spatial frequencies suggests that these spatial-frequency tuning properties are determined by the properties of retinal input cells and not by retinogeniculate convergence patterns.

\section{Relationship of results to $L G N$ cell size}

A striking feature of the LGNs of KVC-1D and KVC-8WK cats is the presence of many large surviving cells that are not present in AVC cats (Table 1, row 2) (Doty, 1961; Wetzel ct al., 1965; Tucker et al., 1968; Mize and Murphy, 1976; Cornwell et al., 1978; Murphy and Kalil, 1979; Spear et al., 1980; Kalil, 1984). However, we found no functional correlate of this difference in LGN cell size. Several observations suggest that our recordings included surviving small LGN cells as well as the large cells. For instance, we were able to record many cells in AVC cats, which have few or no surviving large LGN cells. In addition, there are too few large cells in the KVC-1D and KVC-8WK cats to account for all our recordings in those animals, and the sampling densities in KVC-1D and KVC-8WK cats were similar to that in AVC cats (Table 2). Thus, even though we undoubtedly recorded from surviving cells of all sizes, we found no evidence for functionally distinct groups of cells that might correspond to large and small cells in the KVC cats. In addition, we found no differences between recordings in the $\mathrm{KVC}$ cats, in which
A LAYERS

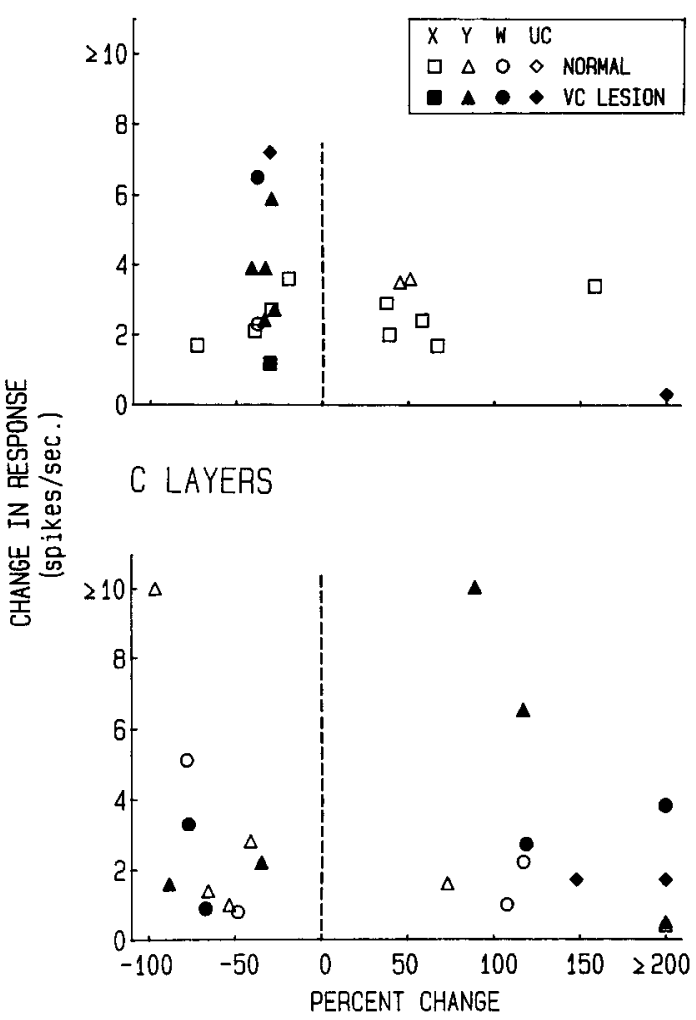

Figure 13. Direction and magnitude of responses to the nondominant eye for cells recorded in the A-layers (top) and C-layers (bottom) of normal cats and cats with a visual cortex lesion. Results are combined for cats that received a lesion at different ages. The nondominant eye was stimulated with $3 \mathrm{~Hz}$ drifting sine-wave gratings of different spatial frequencies. Results are shown for the F0 response to the optimal spatial frequency for each cell that gave a statistically significant response. Each point indicates the absolute change in response (ordinate) and the percentage change in response (abscissa) above (right) or below (left) spontaneous activity during presentation of a blank screen.

many large cells are present, and AVC cats, in which there are few or no large cells. These results suggest that cell size is not necessarily correlated with the functional properties of LGN cells, a conclusion that has been reached previously in studies of visually deprived cats (see Geisert et al., 1982, for a discussion). Perhaps functional properties are related to the neuron's inputs, whereas soma size is related to efferent terminal field size of the parent neuron.

\section{Relationship of results to $L G N$ synaptic reorganization}

Electron microscopic studies show that the synaptic organization of the LGN is very abnormal following both neonatal and adult visual cortex lesions (Table 1, row 3) (Hamori and Silakov, 1980, 1981; Somogyi et al., 1982, 1984; Kalil and Behan, 1987). Of particular relevance to the present study are results reported by Kalil and Behan (1987), who made a detailed quantitative comparison of the retinogeniculate synaptic connections in the A- and C-layers following a chronic visual cortex lesion in 1-dold and adult cats. Kalil and Behan (1987) found that there is a loss of retinal terminals in both groups. In addition, although the average number of synapses made by each surviving terminal is normal, the distribution of the synaptic contacts is abnormal. In both groups, the number of retinal synapses onto 
dendrites decreases and the number onto flat-vesicle-containing profiles increases. Thus, the nature of the synaptic reorganization that occurs following a visual cortex lesion is similar in KVC-1D and AVC cats. However, the 2 conditions differ in the degree of the changes. For instance, the loss of retinal terminals is about twice as large in KVC-1D cats than in AVC cats. In addition, compared with normal adult cats, cats with an adult lesion have a 5 -fold increase in the ratio of retinal synapses onto flat-vesicle-containing profiles relative to those onto relay-cell dendrites in the A-layers and a 2 -fold increase in this ratio in the C-layers. By contrast, in the cats with a visual cortex lesion made on the day of birth, the ratio of flat-vesicle-containing profile to relay-cell dendrite contacts increases 2.5 -fold in the A-layers and 5-fold in the C-layers.

As noted in the previous section and suggested by others (Murphy and Kalil, 1979; Somogyi et al., 1984; Kalil and Behan, 1987), the increase in receptive-field center size among surviving LGN cells may be related to these abnormal synaptic connections (including retinogeniculate convergence patterns) within the LGN. In addition, the loss of retinal terminals may reflect the loss of retinogeniculate $\mathrm{X}$ cell connections in both KVC-1D and AVC cats. However, we found little else in the functional properties of surviving LGN neurons that can be related directly to the changes in synaptic organization after a visual cortex lesion. For example, we found no differences in the properties of cells in cats with neonatal or adult lesions, and we found no differences in abnormalities among $\mathrm{A}$ - and $\mathrm{C}$-layer cells that can readily be attributed to the differences in synaptic reorganization observed by Kalil and Behan (1987). Furthermore, we found no changes in response properties that might be a reflection of the massive increases in the proportion of retinal contacts onto flat-vesicle-containing profiles. Because flat-vesicle-containing profiles are thought to be inhibitory (Sterling and Davis, 1980; Fitzpatrick et al., 1984), we specifically tested for changes in 2 inhibitory functions: strength of receptive-field surround inhibition and nondominant-eye inhibition. Aside from a slight increase in the proportion of cells with nondominant eye inhibition in the degenerated A-layers, we found no significant changes in the incidence or strength of these inhibitory functions.

It is, of course, possible that the synaptic reorganization that occurs in the LGN following neonatal and adult visual cortex damage is related to functional properties that we did not test (such as contrast sensitivity or temporal sensitivity). Alternatively, it may be that many anomalous synaptic contacts are nonfunctional, while other synaptic contacts are normal and lead to normal response properties in the degenerated LGN.

\section{Relationship of results to enhanced projection to, and physiological compensation in, PMLS cortex}

Anatomical studies have demonstrated that an enhanced projection develops from retina through thalamus to PMLS cortex following a visual cortex lesion between birth and 18 weeks of age (Table 2, row 4) (Kalil et al., 1979; Kalil, 1984; Tong et al., 1984). At least a portion of this enhanced projection is relayed through surviving cells in the A- and C-layers of the LGN (Kalil et al., 1979). Physiological compensation also is observed in PMLS cortex following an early visual cortex lesion, and the exact nature of the compensation differs following a lesion at different ages (Table 2, row 5) (Spear et al., 1980; Tong et al., 1984). One purpose of the present study was to assess the re- lationship between the physiological compensation seen in PMLS cortex and the functional properties of LGN cells that provide an input to PMLS cortex. Although we did not determine which, if any, of the recorded LGN cells project to PMLS cortex, in the discussion that follows we tentatively assume that our recordings included, and are representative of, surviving LGN cells that project to PMLS cortex.

One property that shows physiological compensation in PMLS cortex is ocular dominance (Spear et al., 1980; Tong et al., 1984). In normal cats, about $70 \%$ of PMLS cells are driven by both eyes, and nearly all cells can be driven by the contralateral eye. Chronic removal of ipsilateral areas 17 and 18 in adult cats reduces the percentage of cells driven by the ipsilateral eye to about $40 \%$. Following chronic removal of areas 17 and 18 betwecn birth and 18 weeks of age, however, PMLS cells develop normal ocular dominance, and about $70 \%$ of the cells are driven by both eyes, just as in normal adult cats. This ocular-dominance compensation following an early, but not an adult, visual cortex lesion can be accounted for in part by the eye dominance of surviving cells in LGN layers that project to PMLS cortex. As already noted, only the C-layers project to PMLS cortex in AVC cats, and the ratio of ipsilaterally to contralaterally driven cells in these layers is 1:7 (Table 2). In KVC cats, A-layer cells also project to PMLS cortex, and the ratio of ipsilaterally to contralaterally driven cells in these layers is about $1: 1.3$ (Table 2; the ratio is 1.2 to $1: 3$ when the $A-$ and $C$-layers are combined). Thus, if cells in the A-layers of KVC cats exert a strong excitatory influence on PMLS cells, they could produce the nearly balanced ocular dominance of PMLS cells in these animals. This supports previous suggestions (Tong et al., 1984; Spear, 1985; Spear et al., 1988), based on similaritics in critical periods as well as other evidence, that the compensation of ocular dominance in PMLS cortex is based on the enhanced inputs to PMLS cortex from thalamus.

A second property that shows physiological compensation in PMLS cortex is direction selectivity (Spear et al., 1980; Tong et al., 1984). In normal cats, about $80 \%$ of PMLS cells are direction selective. Removal of ipsilateral areas 17 and 18 in adult cats reduces the percentage of direction-selective cells to about 20\%. Following chronic removal of areas 17 and 18 between birth and 12 weeks of age, however, a normal percentage of PMLS cells develops direction selectivity. Our results indicate that this compensation of direction selectivity is not simply a reflection of properties of LGN cells that project to PMLS cortex because we found no direction-selective cells in our LGN recordings. Thus, compensation of direction selectivity appears to be based on other inputs, or, as suggested previously (Tong et al., 1984; Spear, 1985; Spear et al., 1988), it is a result of changes in intracortical PMLS circuitry that develops after an early visual cortex lesion.

A third property that shows compensation in PMLS cortex is orientation selectivity to flashed or moving slits of light (Tong et al., 1984). In normal cats, fewer than 5\% of PMLS cells show orientation selectivity to such stimuli. Following chronic removal of ipsilateral areas 17 and 18 between 2 and 8 weeks of age, about $30 \%$ of PMLS cells are orientation selective. However, few PMLS cells develop orientation selectivity following removal of ipsilateral areas 17 and 18 on the day of birth or at 12 weeks of age or later. Because we found no evidence for orientation selectivity among surviving LGN cells following a visual cortex lesion at any age, the development of this anomalous property in PMLS cortex also is likely to be due to changes 
in intracortical wiring, as suggested previously (Tong et al., 1984; Spear, 1985; Spear et al., 1988).

A puzzle that remains is why anomalous orientation selectivity develops in PMLS cortex following a visual cortex lesion at 2-8 weeks of age but not following a lesion in younger (1-dold) kittens. It has been proposed that $X$ cell inputs might be necessary for the development of orientation selectivity and that few PMLS cells are orientation selective in KVC-1D cats because retinal $\mathrm{X}$ cell inputs are sparse in those animals (Callahan et al., 1984). However, the present results show that the availability of $\mathrm{X}$ cell inputs from LGN to PMLS cortex is equally sparse in KVC-1D and KVC-8WK cats. Therefore, the reason that anomalous orientation selectivity can develop in PMLS cortex after a visual cortex lesion at 2-8 weeks of age but not after an earlier lesion remains a mystery.

\section{Conclusions}

Retrograde degeneration of neurons that project to a damaged area of the brain is a common phenomenon, as is survival of a population of neurons in an otherwise degenerated structure. The present results indicate that, although there are some abnormalities, surviving neurons in at least one structure, the LGN, can have surprisingly normal functional properties. Anatomical studies indicate that many surviving C-layer neurons in cats that received a lesion as adults maintain their normal projection to an undamaged region of the brain (PMLS cortex) and that many of the surviving A- and C-layer neurons provide a new or enhanced projection to PMLS cortex after visual cortex damage early in life. Thus, cells within a structure that shows severe retrograde degeneration after brain damage can take part in potentially important neural pathways. These pathways can show physiological compensation, and they may contribute to behavioral recovery from the effects of early or late brain damage (see Spear, 1979, 1985).

\section{References}

Bishop, P. O. (1965) The nature of the representation of the visual fields in the lateral geniculate nucleus. Proc. Austr. Assoc. Neurol. 3: 15-25.

Bishop, P. O., W. Burke, and R. Davis (1962a) The identification of single units in central visual pathways. J. Physiol. (Lond.) 162: 409431.

Bishop, P. O., W. Kozak, W. R. Levick, and G. J. Vakkur (1962b) The determination of the projection of the visual field onto the lateral geniculate nucleus in the cat. J. Physiol. (Lond.) 163: 503-539.

Bowling, D. B., and C. R. Michael (1984) Terminal patterns of single, physiologically characterized optic tract fibers in the cat's lateral geniculate nucleus. J. Neurosci. 4: 198-216.

Bowling, D. B., and E. Wieniawa-Narkiewicz (1986) The distribution of on- and off-centre X-and Y-like cells in the A layers of the cat's lateral geniculate nucleus. J. Physiol. (Lond.) 375: 561-572.

Bowling, D. B., and E. Wieniawa-Narkiewicz (1987) Differences in the amplitude of X-cell responses as a function of depth in layer $A$ of lateral geniculate nucleus in cat. J. Physiol. (Lond.) 390: 201-212.

Bullier, J., and T. T. Norton (1979) X and Y relay cells in cat lateral geniculate nucleus: Quantitative analysis of receptive-field classification. J. Neurophysiol. 42: 244-273.

Burrows, G. R., and W. R. Hayhow (1971) The organization of the thalamo-cortical pathways in the cat. An experimental degeneration study. Brain Behav. Evol. 4: 220-270.

Callahan, E. C., L. Tong, and P. D. Spear (1984) Critical period for the marked loss of retinal $\mathrm{X}$-cells following visual cortex damage in cats. Brain Res. 323: 302-306.

Chow, K. L., and J. H. Dewson (1966) Numerical estimates of neurons and glia in lateral geniculate body during retrograde degeneration. $\mathrm{J}$. Comp. Neurol. 128: 63-73.
Chow, K. L., and D. F. Lindsley (1969) Microelectrode study of residual neurons in the degenerated lateral geniculate nucleus of the cat. J. Neurophysiol. 32: 116-126.

Cleland, B. G., M. W. Dubin, and W. R. Levick (1971) Sustained and transient neurones in the cat's retina and lateral geniculate nucleus. J. Physiol. (Lond.) 217: 473-496.

Cleland, B. G., W. R. Levick, R. Morstyn, and H. G. Wagner (1976) Lateral geniculate relay of slowly conducting retinal afferents to cat visual cortex. J. Physiol. (Lond.) 255: 299-320.

Cornwell, P., W. Overman, and C. Ross (1978) Extent of recovery from neonatal damage to the cortical visual system in cats. J. Comp. Physiol. Psychol. 92: 255-270.

Crabtree, J. W., P. D. Spear, M. A. McCall, L. Tong, K. R. Jones, and S. E. Kornguth (1986) Dose-response analysis of effects of antibodies to large ganglion cells on the cat's retinogeniculate pathways. J. Neurosci. 6: 1199-1210.

Derrington, A. M., and A. F. Fuchs (1979) Spatial and temporal properties of $\mathrm{X}$ and $\mathrm{Y}$ cells in the cat lateral geniculate nucleus. J. Physiol. (Lond.) 293: 347-364.

Doty, R. W. (1961) Functional significance of the topographical aspects of the retinocortical projection. In The Visual System: Neurophysiology and Psychophysics, R. Jung and H. Kornhuber, eds., pp. 228-247, Springer-Verlag, Berlin.

Enroth-Cugell, C., and J. G. Robson (1966) The contrast sensitivity of retinal ganglion cells of the cat. J. Physiol. (Lond.) 187: 517-552.

Fitzpatrick, D., G. R. Penny, and D. E. Schmechel (1984) Glutamic acid decarboxylase-immunoreactive neurons and terminals in the lateral geniculate nucleus of the cat. J. Neurosci. 4: 1809-1829.

Frascella, J., and S. Lehmkuhle (1984) A comparison between Y-cells in A-laminae and lamina $\mathrm{C}$ of cat dorsal lateral geniculate nucleus. J. Neurophysiol. 52: 911-920.

Friedlander, M. J., and L. R. Stanford (1984) Effects of monocular deprivation on the distribution of cell types in the LGNd: A sampling study with fine-tipped micropipettes. Exp. Brain Res. 53: 451-461.

Friedlander, M. J., C.-S. Lin, L. Stanford, and S. M. Sherman (1981) Morphology of functionally identified neurons in the lateral geniculate nucleus of the cat. J. Neurophysiol. 46: 80-129.

Garey, L. J., and T. P. S. Powell (1967) The projection of the lateral geniculate nucleus upon the cortex in the cat. Proc. R. Soc. London [Biol.] 169: 107-126.

Geisert, E. E., P. D. Spear, S. Zetlan, and A. Langsetmo (1982) Recovery of Y-cells in the lateral geniculate nucleus of monocularly deprived cats. J. Neurosci. 2: 577-588.

Guido, W., N. Tumosa, and P. D. Spear (1989) Binocular interactions in the cat's dorsal lateral geniculate nucleus. I. Spatial-frequency analysis of responses of $X, Y$, and $W$ cells to nondominant-eye stimulation. J. Neurophysiol. (in press)

Hamori, I., and V. L. Silakov (1980) Plasticity of relay neurons in dorsal lateral geniculate nucleus of the adult cat: Morphological evidence. Neuroscience 5: 2073-2077.

Hamori, J., and V. L. Silakov (1981) Myelinated perikarya and dendrites in lateral geniculate nucleus of adult cat following chronic cortical deafferentation. J. Neurocytol. 10:879-888.

Hochstein, S., and R. M. Shapley (1976) Quantitative analysis of retinal ganglion cell classifications. J. Physiol. (Lond.) 262: 237-264.

Hoffmann, K.-P., J. Stone, and S. M. Sherman (1972) Relay of receptive-field properties in dorsal lateral geniculate nucleus of the cat. J. Neurophysiol. 35: 518-531.

Kalil, R. E. (1978) Projection of the retina to the lateral geniculate nucleus in the cat following neonatal ablation of visual cortex. Soc. Neurosci. Abstr. 4: 633.

Kalil, R. E. (1984) Removal of visual cortex in the cat: Effects on the morphological development of the retino-geniculo-cortical pathway. In Development of Visual Pathways in Mammals. J. Stone, B. Dreher, and D. H. Rapaport, eds., pp. 257-274, Liss, New York.

Kalil, R. E., and M. Behan (1987) Synaptic reorganization in the dorsal lateral geniculate nucleus following damage to visual cortex in newborn or adult cats. J. Comp. Neurol. 257: 216-236.

Kalil, R. E., L. Tong, and P. D. Spear (1979) Reorganization of the geniculocortical pathway in the cat following neonatal damage to visual cortex. Invest. Ophthalmol. Vis. Sci. Suppl. 18: 157.

Kaplan, E., S. Marcus, and Y.-T. So (1979) Effects of dark adaptation on spatial and temporal properties of receptive fields in cat lateral geniculate nucleus. J. Physiol. (Lond.) 294: 561-580.

Kratz, K. E., S. V. Webb, and S. M. Sherman (1978) Electrophysio- 
logical classification of $\mathrm{X}$ - and $\mathrm{Y}$-cells in the cat's lateral geniculate nucleus. Vision Res. 18: 1261-1264.

Lehmkuhle, S., K. E. Krak, S. C. Mangel, and S. M. Sherman (1980) Spatial and temporal sensitivity of $\mathrm{X}$ - and $\mathrm{Y}$-cells in dorsal lateral geniculate nucleus of the cat. J. Neurophysiol. 43: 520-541.

McCall, M. A., P. D. Spear, J. W. Crabtree, and S. E. Kornguth (1987) Effects of antibodies to large retinal ganglion cells on developing retinogeniculate pathways in the cat. Dev. Brain Res. 34: 223-233.

Mitzdorf, U., and W. Singer (1977) Laminar segregation of afferents to lateral geniculate nucleus of the cat: An analysis of current source density. I. Neurophysiol. 40: 1227-1244.

Mize, R. R., and E. H. Murphy (1976) Alterations in receptive field properties of superior colliculus cells produced by visual cortex ablation in infant and adult cats. J. Comp. Neurol. 168: 393-424.

Murphy, E. H., and R. E. Kalil (1979) Functional organization of lateral geniculate cells following removal of visual cortex in the newborn kitten. Science 206: 71-716.

Niimi, K., and J. M. Sprague (1970) Thalamocortical organization of the visual system in the cat. J. Comp. Neurol. 138: 219-250.

Otsuka, R., and R. Hassler (1962) Uber Aufbau und Gliederung der corticalen Sehsphare bei der Katze. Arch. Psychiatr. Z. Neurol. 203: 212-234.

Payne, B. R., H. E. Pearson, and P. Cornwell (1984) Transneuronal degeneration of beta retinal ganglion cells in the cat. Proc. R. Soc. London [Biol.] 222: 15-32.

Pearson, H. E., D. R. Labar, B. R. Payne, P. Cornwell, and N. Aggarwal (1981) Transneuronal retrograde degeneration in the cat retina following neonatal ablation of visual cortex. Brain Res. 212: 470-475.

Pettigrew, J. D., M. L. Cooper, and G. G. Blasdel (1979) Improved use of tapetal reflection for eye position monitoring. Invest. Ophthalmol. Vis. Sci. 18: 490-495.

Rosenquist, A. C. (1985) Connections of visual cortical areas in the cat. In Cerebral Cortex, A. Peters and E. G. Jones, eds., pp. 81-117, Plenum, New York.

Sanderson, K. J. (1971a) Visual field projection columns and magnification factors in the lateral geniculate nucleus of the cat. Exp. Brain Res. 13: 159-177.

Sanderson, K. J. (1971b) The projection of the visual field to the lateral geniculate and medial interlaminar nuclei in the cat. J. Comp. Neurol. 13: 101-118.

Shapley R., and S. Hochstein (1975) Visual spatial summation in two classes of geniculate cells. Nature 256: 411-413.

So, Y.-T., and R. M. Shapley (1979) Spatial properties of X and Y cells in the lateral geniculate nucleus of the cat and conduction velocities of their inputs. Exp. Brain Res. 36: 533-550.

So, Y.-T., and R. M. Shapley (1981) Spatial tuning of cells in and around lateral geniculate nucleus of the cat: $X$ and $Y$ relay cells and perigeniculate interneurons. J. Neurophysiol. 45: 107-120.

Somogyi, J., J. Hamori, and V. L. Silakov (1982) Free postsynaptic sites in the lateral geniculate nucleus of adult cats following chronic decortication. Cell Tissue Res. 225: 437-442.

Somogyi, J., J. Hamori, and V. L. Silakov (1984) Synaptic reorganization in the lateral geniculate nucleus of the adult cat following chronic decortication. Exp. Brain Res. 54: 485-498.

Spear, P. D. (1979) Behavioral and neurophysiological consequences of visual cortex damage: Mechanisms of recovery. In Progress in Psychobiology and Physiological Psychology, J. M. Sprague and A. N. Epstein, eds., pp. 45-90, Academic, New York.

Spear, P. D. (1985) Neural mechanisms of compensation following neonatal cortex damage. In Synaptic Plasticity and Remodeling, C. W. Cotman, ed., pp. 111-167, Guilford, New York.

Spear, P. D., and T. P. Baumann (1979) Effects of visual cortex re- moval on receptive-field properties of neurons in lateral suprasylvian visual area of the cat. J. Neurophysiol. 42: 31-56.

Spear, P. D., R. E. Kalil, and L. Tong (1980) Functional compensation in lateral suprasylvian visual area following neonatal visual cortex removal in cats. J. Neurophysiol. 43: 85I-869.

Spear, P. D., K. R. Jones, S. Zetlan, E. E. Geisert, and S. Kornguth (1982) Effects of antibodies to large ganglion cells on the cat's retinogeniculate pathway. J. Neurophysiol. 47: 1174-1195.

Spear, P. D., L. Tong, and M. A. McCall (1988) Functional influence of areas 17, 18, and 19 on lateral suprasylvian cortex in kittens and adult cats: Implications for compensation following early visual cortex damage. Brain Res. 447: 79-91.

Spear, P. D., M. A. McCall, and N. Tumosa (1989) W and Y cells in the C layers of the cat's lateral geniculate nucleus: Normal properties and effects of monocular deprivation. J. Neurophysiol. (in press).

Stanford, L. R., M. L. Friedlander, and S. M. Sherman (1983) Morphological and physiological properties of geniculate $\mathrm{W}$-cells of the cat: A comparison with X-and Y-cells. J. Neurophysiol. 50: 582608.

Sterling, P., and T. L. Davis (1980) Neurons in cat lateral geniculate nucleus that accumulate exogenous [3H]-gamma-aminobutyric acid (GABA). J. Comp. Neurol. 192: 737-749.

Sur, M., and S. M. Sherman (1982) Linear and nonlinear W-cells in C-laminae of the cat's lateral geniculate nucleus. J. Neurophysiol. 43. 869-884

Sur, M., M. Esguerra, P. E. Garraghty, M. F. Kritzer, and S. M. Sherman (1987a) Morphology of physiologically identified retinogeniculate Xand $\mathrm{Y}$-axons in the cat. J. Neurophysiol. 58: 1-32.

Sur, M., A. W. Roe, and P. E. Garraghty (1987b) Evidence for early specificity of the retinogeniculate X-cell pathway. Soc. Neurosci. Abstr. I3: 589.

Tong, L., P. D. Spear, R. E. Kalil, and E. C. Callahan (1982) Loss of retinal X-cells in cats with neonatal or adult visual cortex damage. Science 217: 72-75.

Tong, L., R. E. Kalil, and P. D. Spear (1984) Critical periods for functional and anatomical compensation in lateral suprasylvian visual area following removal of visual cortex in cats. J. Neurophysiol. 52; 941-960.

Troy, J. B. (1983) Spatial contrast sensitivities of $X$ and $Y$ type neurons in the cat's dorsal lateral geniculate nucleus. J. Physiol. (Lond.) 34: $399-418$.

Tucker, T. V., A. Kling, and D. P. Scharlock (1968) Sparing of photic frequency and brightness discriminations after striatectomy in neonatal cats. J. Neurophysiol. 31: 818-832.

Tusa, R. J., L. A. Palmer, and A. C. Rosenquist (1978) The retinotopic organization of area 17 (striate cortex) in the cat. J. Comp. Neurol. 177: 213-236.

Tusa, R. J., A. C. Rosenquist, and L. A. Palmer (1979) Retinotopic organization of areas 18 and 19 in the cat. J. Comp. Neurol. 185: $657-678$

Weber, A. J., L. R. Stanford, and R. E. Kalil (1986) Morphology of single retinogeniculate axons in cats with early visual cortex lesions. Invest. Ophthalmol. Vis. Sci. Suppl. 27: 205.

Wetzel, A. B., V. E. Thompson, J. A. Horel, and P. M. Meyer (1965) Some consequences of perinatal lesions of the visual cortex in the cat. Psychon. Sci., 3: 381-382.

Wilson, P. D., M. H. Rowe, and J. Stone (1976) Properties of relay cells in cat's lateral geniculate nucleus: A comparison of W-cells and X- and Y-cells. J. Neurophysiol. 39: 1193-1209.

Wood, C. C., P. D. Spear, and J. J. Braun (1974) Effects of sequential lesions of suprasylvian gyri and visual cortex on pattern discrimination in the cat. Brain Kes. 66: 443-466. 